\title{
Boundary Explorations: The Redefinition of an Arts Precinct in the Urban Fabric of Ottawa
}

\author{
By \\ Joyce Baddour, B.A.S.

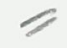 \\ A thesis submitted to \\ the Faculty of Graduate Studies and Research \\ in partial fulfillment of the requirements for the degree of
}

Master of Architecture

Carleton University

Ottawa, Ontario

June 2006

(C) 2006, Joyce Baddour 


\begin{abstract}
A great deficiency in the current urban condition is the disjuncture in the relationship between a parcel of land that is prescribed for a piece of architecture, and the urban environment. This thesis explores strategies that can be used to integrate the architecture of a site with the architecture of the city, through the development of new relationships in reconfiguration to existing conditions. The Arts Court is a clear case of an isolated complex of historical buildings that has become a preserved icon. Along with its adjacent land, the Arts Court is being used to test the design of boundaries that lend to a reinterpretation of its role in the city as an Arts Precinct.
\end{abstract}




\section{Abstract}

A great deficiency in the current urban condition is the disjuncture in the relationship between a parcel of land that is prescribed for a piece of architecture, and the urban environment. This thesis explores strategies that can be used to integrate the architecture of a site with the architecture of the city, through the development of new relationships in reconfiguration to existing conditions. The Arts Court is a clear case of an isolated complex of historical buildings that has become a preserved icon. Along with its adjacent land, the Arts Court is being used to test the design of boundaries that lend to a reinterpretation of its role in the city as an Arts Precinct. 


\section{Acknowledgments}

I wish to thank Professor Lucie Fontein, my thesis supervisor, for her patience, guidance, and continuous support in this process. I would like to extend my appreciation to my parents, brother and sister for their unwavering support throughout the six years of my education in Architecture, and to my fiance for his encouragement in completing this degree. Finally, I want to acknowledge Professors Yvan Cazabon and Thomas Mical for their valuable contributions. 


\section{Table of Contents}

1 Introduction 1

1.1 Context 1

1.2 Contrasting Roles 2

1.3 The Arts Precinct 4

2 Redefinition of the Urban Boundaries 6

2.1 History of the Urban Condition 6

2.2 Possible Design Approaches $\quad 8$

$\begin{array}{lll}2.3 & \text { Urban Design Strategies } & 10\end{array}$

2.3.1 Programmatic Development 11

$\begin{array}{lll}2.3 .2 & \text { Accessibility } & 12\end{array}$

2.3.3 Redefinition of the Site Edges 13

$\begin{array}{ll}\text { 2.3.4 Refocusing of the Site as a Destination } & 14\end{array}$

$\begin{array}{ll}\text { 2.3.5 Stimulating Multiple Interpretations } & 16\end{array}$

3 Redefinition of the Architectural Boundaries $\quad 17$

3.1 History of the Building to Date 17

$\begin{array}{lll}3.2 & \text { Possible Approaches } & 19\end{array}$

3.3 Scarpa as Precedent 21

3.3.1 Scarpa's Attitude Towards History 23

3.3.2 Amplification 24

3.3.3 Redefinition of the Role of the Wall 26

3.3.4 Architecture as Narrative 28

3.3.5 The Detail 31 
3.3.6 General Implications for the Arts Precinct 33

4 Redefinition of the Boundaries found within Art Discourse 40

$\begin{array}{lll}4.1 & \text { Introduction } & 40\end{array}$

4.2 The Realm of the Artist 43

4.3 The Realm of the Viewer 44

4.4 The Shared Realm 45

5 Conclusion $\quad 48$

$\begin{array}{ll}\text { Bibliography } & 51\end{array}$

Appendix A: Images and Drawings 53 


\section{List of Figures}

Figure 1: 1888 Site map $\quad 6$

$\begin{array}{ll}\text { Figure 2: } 1912 \text { Site map } & 6\end{array}$

$\begin{array}{ll}\text { Figure 3: Site 1915: urban context } & 7\end{array}$

Figure 4: Site 1956: Future sites of high rise hotels and the Rideau Centre 7

Figure 5: Site 2003. Darker tones represent newer buildings 8

Figure 6: Identification of major urban boundaries 13

Figure 7: Identification of major boundaries within the site 14

Figure 8: An urban conservation project in Albert Lea, Minnesota 20

Figure 9: A view through the architectural intervention "Conical Intersect" 20

Figure 10: A view of the castle 22

Figure 11: A view to the city of Verona from an essential juncture 23

Figure 12: View of multiple planes $\quad 24$

Figure 13: View of a bridge that crosses exposed layers of the original foundations 24

Figure 14: View of gallery space and exhibit installations 24

Figure 15: Display interstices on ground floor of Courthouse 25

Figure 16: Elusive of walls 26

Figure 17: South-East approach into the building 26

$\begin{array}{ll}\text { Figure 18: West elevation } & 27\end{array}$

$\begin{array}{ll}\text { Figure 19: Transition to resource centre } & 27\end{array}$

Figure 20: View of the statue $\quad 28$

Figure 21: Cangrande della Scala 28

Figure 22: Release of pathways into space of display 29 
Figure 23: Main circulation on second floor

Figure 24: View of exhibition installation as armature for display

Figure 25: Space between old and new fabric

Figure 26: Movement through the building

Figure 27: 24-hour passage leads to a café facing Nicolas Street

Figure 28: Artists' studios along jail wall. Condominium building on right

Figure 29: Balcony space

Figure 30: Market approach to the Precinct from the North

Figure 31: Slippage of structure to plaza space

Figure 32: Screen defined as a boundary along Waller Street

Figure 33: Site periphery along Waller Street

Figure 34: South-facing studios extend beyond jail wall to shelter stairway 43

Figure 35: From sheltered stairway. Objects displayed overhead

Figure 36: Approach from North side

Figure 37: Visual access through pulley system 


\section{List of Appendices}

Appendix A: Images and Drawings 


\section{Introduction}

\subsection{Context}

A great deficiency in the current urban condition is that the architectural project ends at the boundary of its site. One can point to many instances in the city where it is clear that little consideration has been given to the connection between the urban environment and a parcel of land designated for a piece of architecture. This thesis explores strategies that can be used to integrate the architecture of a site with the architecture of the city. More specifically, it will consider the particular conditions surrounding the redevelopment of a building site that includes a historic building. In such cases, the disjuncture between the site and the city is further amplified by the site's status as a protected, preserved and fossilized icon. How can a designated heritage building be dealt with in a way that enhances its connections to the contemporary city?

Today, conventional views of the preservation of historic buildings are based on an approach that aims to maintain the building's original condition. In many cases however, its programmatic functions are changed. It is a common occurance that elements of the original architecture, which at one time may have served to connect the building to its surroundings, cease to make sense in their new context. For example, historically, a fence placed in front of a building may have been articulated as a deliberate preface to the entry sequence, standing as a defining element in its relationship to the site and its surroundings. Now, the same fence may simply have become a security device. The act of preserving the "value" of a historic building for the sake of preservation must therefore 
be carefully scrutinized and reevaluated in the context of the changing city and changing needs of the property. What strategies can be invoked to enable the reinterpretation of a heritage site in such a way as to not only establish its role as a cultural artifact that embodies a living history of the city, but also draws attention to new possibilities for its relationship to the city?

The questions raised by the thesis have been explored in the design proposal for an Arts Precinct on the existing site of the Arts Court. Located adjacent to the Rideau Centre in Downtown Ottawa, a virtual island squeezed between the northbound Waller Street offramp and the Nicholas Street on-ramp to the Queensway Expressway, the new programs that occupy this former Court House and Jail precinct suffer tremendously from a lack of connection to the surrounding urban fabric. A careful study of the history of the site and the urban design decisions that have resulted in this condition, establish the ground for the development of design strategies that will begin to "heal" the spatial, temporal and programmatic rifts or boundaries that have been created within the urban fabric. The design process has therefore been based on boundary studies both at the urban and architectural levels as well as an exploration into the boundaries that exist within art discourse that stem from the relationship between the artist and the viewer and the tension that exists between the production and display of art.

\subsection{Contrasting Roles}

An exploration into ways to approach a historic site brings into question a spectrum of roles for the architect; from the conservator at one extreme, to the artist/critic at the other, ranging in order from least to most invasive. 
The conservator, responsible for the heritage protection of the site, would have little concern for its isolation from the city and the nature of the boundaries that define it. The approach of such a figure would most likely result in minor adjustments to the existing construction to accommodate the new program and mechanical systems.

To conserve is to affirm the need for a decision to be made regarding what is done with heritage property. Whether that action involves approaches towards the protection, communication, or transformation of heritage properties, the word itself reveals the vulnerable position in which heritage values lie. What is not acknowledged by the conservator however, is the capacity of a building in its very vulnerability to express its evolution, or continuum. This notion of continuity is central to the need to reevaluate the perception of heritage situations where the tendency is to isolate them as objects independent of their surroundings.

At the other extreme, the artist/critic might take a much more aggressive approach towards the built fabric and make a much more provocative urban intervention: Gordon Matta-Clark for instance, would make a deep incision into the wall of the building to bracket one's expectations of the threshold between the realm of the live city and that of the impenetrable historicity. Many, particularly the conservators, would find such actions completely unacceptable and a violation to the integrity of the historic artifact. In dealing with a historic site, the architect must position him/herself within this spectrum. I believe that Carlo Scarpa's work, particularly his renovation of the Castelvecchio in Verona, represents a middle ground between these two extremes. While being acutely 
sensitive to the existing fabric, his architectural insertions serve as a critical interpretation of the materials used, spaces inhabited and works exhibited. The design strategies that he used to engage the different boundary conditions of his project have served as a guide to my own work on the Arts Precinct.

\subsection{The Arts Precinct}

The proposed project is to create an Arts Precinct as a place for public discourse.

Evaluating existing conditions that have contributed to the isolation of the site from the city has enabled a somewhat intuitive design approach to the redefinition of its boundary conditions. The project serves as a means to test my attitude towards the fossilized historic site as part of a continuous process of urban transformation. As Ottawa's centre for the performing, visual, literary and media arts, it will include research, educational, artistic and residential components, with their corresponding curatorial, preparatory and operational aspects of the production involved with each activity. The intention is to support the political and social activity that enables the creation of critical frameworks in art discourse by enabling relationships between artists of different media, celebrating commonalities in the creative processes of their work, clarifying the nature of educational space and operational space, and stimulating the viewers' awareness of how they relate to and experience art works.

In principle, the activities at the Arts Court currently form a very public program.

However, it suffers from severe isolation both from the perspective of those who occupy the spaces of the building and the perspective of the site with respect to the city. The Arts Precinct is intended to remedy this situation. It is a celebration of making art; a place of 
live art. It thrives on immersing the public exhibit within the processes of artistic activity and the production of art. It questions the moment at which a work is to be displayed in its final form, relying on the viewer or passer-by as narrator in the spatial canvas of the Precinct. In order to focus on the production of art, the Precinct integrates an artist-inresidence program in such a way as to challenge the traditional gallery phenomenon of display alone. The larger studios and auditorium space of the Visual Arts program contribute a strong production oriented and public dimension to the site. Similarly the production aspects of the curatorial functions, such as the exhibition preparation spaces, are highlighted. Bringing these areas of the program into prominence and juxtaposing them with the exhibition activities, removes the gallery space from its formerly exclusive domain.

If art can be seen as the realm where ideas and values are actively created, given form and mobilized, then the capacity of art to experiment with the parameters of thought, to shape and sculpt our intellect is revealed. Metaphorically, architecture can experiment with the parameters of existing conditions, to sculpt thought and shape the work. Both do not merely reflect social experience and become a product of history but propel thought, discourse and experience forward. Architecture has the capacity to support a new way for the Arts to exist in space and thus enable discourse among different modes of representation. 


\section{Redefinition of the Urban Boundaries}

\subsection{History of the Urban Condition}

The greatest transformations to the site occurred as a result of infrastructural changes. The construction of the Mackenzie King Bridge altered not only the site but its scale, as well as patterns of movement around the site. The movement of trucks and buses, and the surrounding freeway, contribute to high noise levels and a loss of focus that the Courthouse Precinct once commanded. It also ushered in a period of construction of massive building projects in the neighbouring lots.

Originally the site was defined by its own internal road, Courthouse Avenue, and was related in scale to its surroundings which were predominantly the Parliament Buildings and the Train Station. The Courthouse site was a destination. A street was proposed in 1915 to build an even stronger connection between it and these two landmarks, however these projects were never carried out and over time the site gradually lost the sense of scale it

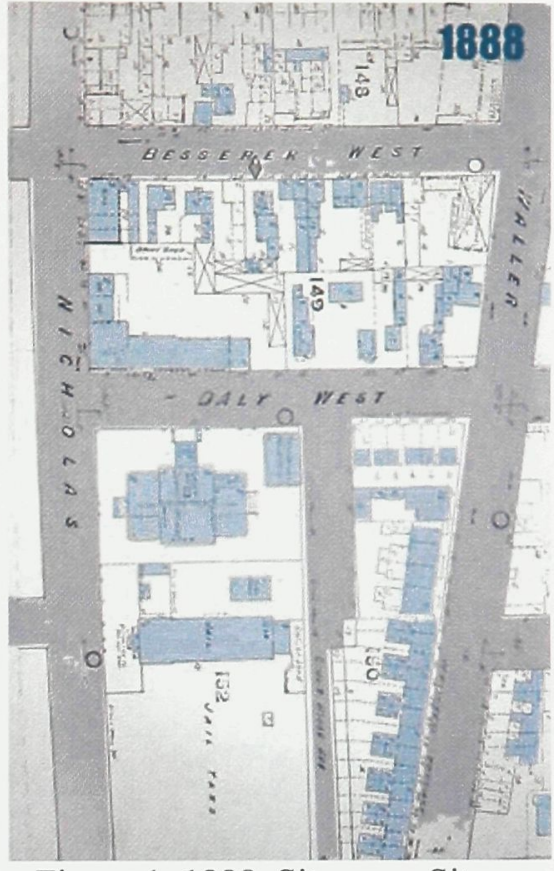

Figure 1. 1888 Site map. Site transformation.

Insurance Plan of the City of Ottawa, $1888,8$.



Figure 2. 1912 Site map. Insurance Plan of the City of Ottawa, 1912, 9. had originally established with its surroundings. 
Transformation did not only happen outside the site. Additions to the courthouse itself in 1953 and 1963, which occurred following the demolition of the constabulary office, greatly impacted the relationship of the courthouse to its surroundings. The additions on the east and south sides were meant to connect the Courthouse with the Registry Office. This resulted in alterations of the exterior character of the Courthouse and therefore its historical significance, as well as internal spatial and functional problems for what was to become an arts institution. The additions of 1953 and 1963 do not have a good relationship to the existing buildings or to their surroundings. The physical connections between old and new were not well thought out. Space had been mostly accommodated by office or

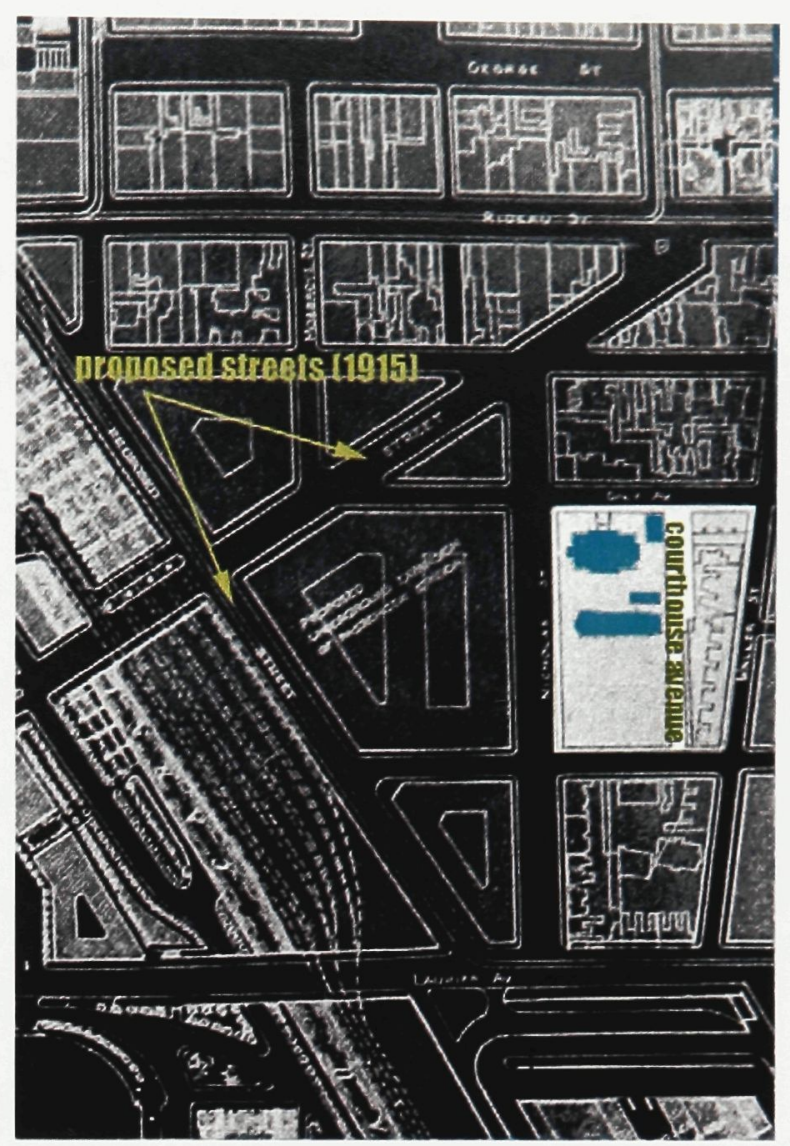

Figure 4. Site 1915: urban context showing proposed street and internal avenue with connections to adjacent lands.

Plan of Municipal and Railway Centre, courtesy of City of Ottawa Archives, 2005.

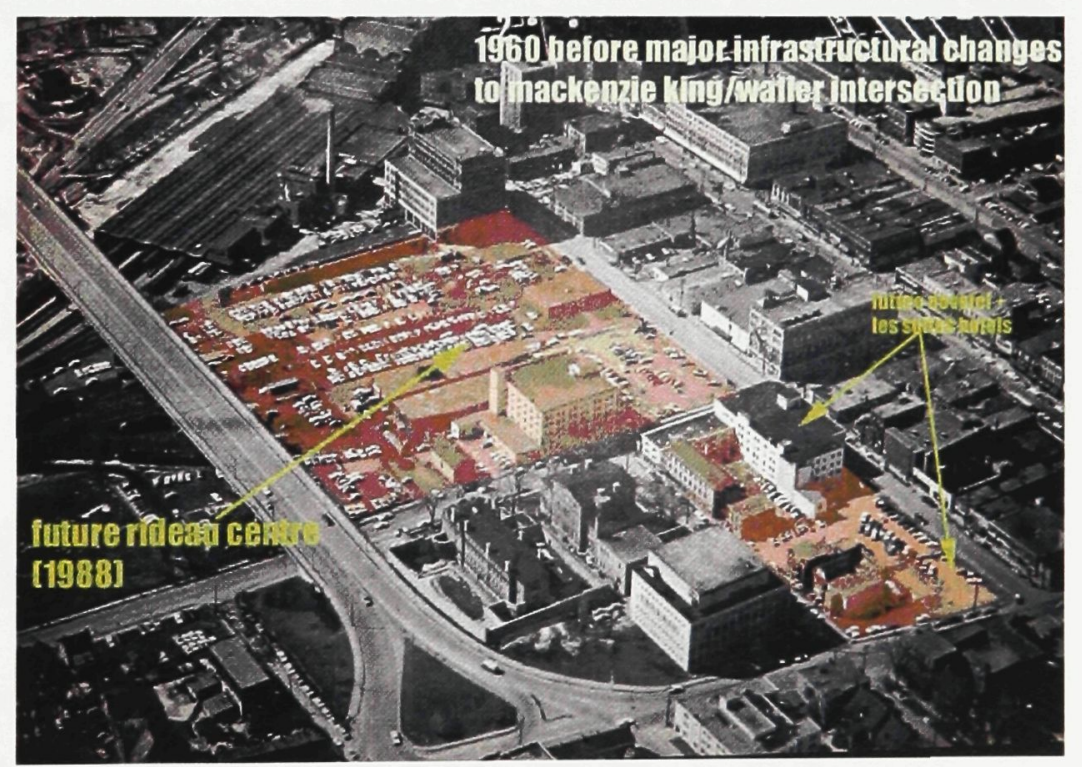

Figure 3. Site 1956: Future sites of high rise hotels and the Rideau Centre. Train Station shown in upper left hand corner. Air photo, 1956: Confederation Square Development, Volume 1, 1962. 
storage space with little or no consideration of how one orients oneself within.

The connections that the site formerly established with the city progressively worsened with the construction of the neighbouring Rideau Center and massive hotels built in the 1980's. Adjacent to the

Courthouse is the Old Ottawa Jail, now operating as a youth hostel. The surrounding jail wall was not part of the original jail but was added later. The most recent changes occurred as a result of the reconstruction of the major intersection to the South of the site: a parcel of land that will accommodate the future Ottawa University Multidisciplinary building, which is itself adjacent to a 16-storey condominium building-all serving to further diminish and isolate the site of the Courthouse.

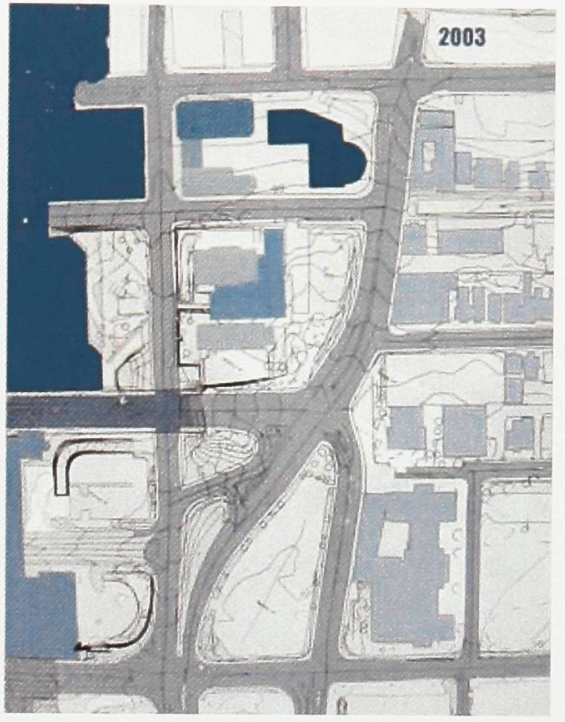

Figure 5. Site 2003. Darker tones represent newer buildings. Facing the jail at the south of the site is the future site of the campus building.

Underlay from 2003 City of Ottawa topographic maps, GIS Data Catalogue in MADGIC,

Today the site has effectively been turned into an island; it is lost, dark and desolate with no way of marking its presence. Neighboring inhabitants have little awareness of the events and activities that take place there, nor what the mandate of the arts centre really is. It is generally perceived as being rather anonymous.

\subsection{Possible Design Approaches}

At the urban level the conservator's approach to design becomes virtually impossible. Except in extremely controlled situations where entire sections of the city have been taken over by a government organization and designated as a historic district (Old 
Havana for example), the transformations to the urban fabric over time become irreversible. Attempts in the North American context, to deny the preeminence of the car usually result in failure.

Similarly, it requires an extremely strong municipal government to implement a more incisive urban plan. The expropriation of buildings to enable a larger urban vision is usually met with considerable resistance (witness the reaction to the proposal to widen Metcalfe Street from the Queensway to the Parliament Buildings). Rarely, therefore, is there any attempt to plan beyond the boundaries of the site.

A third, middle ground strategy is possible, however. The existing layout of an area reflects its history, functions and connections with its surroundings. In some cases, the resulting conditions may reflect a less than sensitive planning history that caused isolation between the architecture and the public realm. However the very same relationships may also become the catalyst for the interest and richness of new development of the site and can contribute to its potential to accommodate further change in the future. Integrating existing buildings and structures into new development can not only maintain the continuity of the built fabric but can also enhance a sense of place by allowing for a new understanding of the role of buildings that transcends their internalized and purely functional purposes. Treating existing buildings in this way enables a regeneration that goes beyond a stagnant maintenance and preservation. It both preserves urban heritage and enhances the living conditions of the city's inhabitants; demanding that we reevaluate our perception of the city's transformation. 


\subsection{Urban Design Strategies}

A number of factors contribute to the failure of the Arts Court to truly engage the community:

- It is surrounded by inhospitable streets that do not respond to the pedestrian scale.

- The front entrance is removed from the sidewalk by a formal and intimidating staircase.

- The site is surrounded by massive buildings that radically restrict views to the site from more active urban nodes.

- The site itself is surrounded by a variety of walls that were relevant to its original function as a police/courthouse precinct. The walls around the site that originally acted as connecting elements through their symbolic value, now do nothing more than reinforce the isolation of the site. One is left with what seems to be the essential disassociation between the place and what happens there. This is the only boundary most people seem to be sensitized to.

Even though it is Ottawa's major municipal arts community the Arts Court had difficulty obtaining government funding resulting in its being little more than a small faction with little identity. ${ }^{1}$ Arts Court was always meant to be a showcase for the arts in the city but it as it stands, it functions primarily as a service building facility for local arts groups. In the process of establishing itself as a municipal arts center it appealed to many educational

\footnotetext{
${ }^{1}$ Ottawa Arts Court Foundation. Pre-Feasibility Needs Assessment \& Best Practice Analysis 2: Needs Assessment/Stakeholder Consultation, 2006. p.17.
} 
institutions but the support offered did not amount to enough to flourish with significant impact on the city.

The thesis project proposes to counteract these problems by engaging a number of strategies that redefine problematic relationships.

\subsubsection{Programmatic Development}

The static institutionalized world of gallery art can be stimulated by an animated world of art that is responsive to the community. The Arts Court was not purpose built for the arts and as such, is suffering from problems that have essentially arisen from lack of communication between its users and the public. To date, the distribution of program into the existing buildings has been haphazard at best, finding band-aid solutions to immediate problems rather than considering the full potential of the proximity of the diverse occupant groups. With a more clearly articulated vision for the internal workings of the Arts Precinct that captures the creative energy of artistic endeavors and the desire to engage in critical discourse, a much more coherent image can be projected to the city. As it stands, the building does not communicate its presence in any way, beyond the use of signage, to invite the public in. The new scheme however, communicates much more effectively by establishing a spatial address rather than a one-sided address. The various components to the precinct such as the performing, educational, exhibit, and residential all serve to articulate the spatial address in the way they are interwoven with one another to draw the city in. 


\subsubsection{Accessibility}

At the most basic level, for an institution such as an arts precinct to succeed, it must be accessible to people of all ages and mobility, arriving on foot or via car or bus. One of the first design moves, therefore, was to consider all possible connections to and across the site as opportunities to be developed.

Two highly used but derelict pathways were identified to establish a connection to the market area of Ottawa. One traverses the site in an east-west direction, connecting the University of Ottawa campus to the Rideau Center/stair on Nicholas Street to the Mackenzie Bridge. The other recognizes a north-south connection through the service lane of the Novotel to the top of Dalhousie Street. These paths in turn formed starting points for interaction with the spaces they traverse. Both paths culminate at a corner entrance facing the curve in Waller Street and the Ottawa University campus, forming the main University approach. This corner doubles as the primary psychological access point for vehicular traffic as it enters Ottawa on Waller Street. The actual vehicular drop-off and parking access takes place on Daly. Finally, the city projects that the O-Train extension will cross Waller into the University campus; the plaza encourages a link to it through active movement patterns around the site. In all instances, the entrances are more or less at grade (i.e. are wheelchair accessible), promoting a much more public and welcoming image to the precinct. 


\subsubsection{Redefinition of the Site Edges}

Visibility from its surroundings is a critical issue in defining one of the boundaries

between the site and its surroundings. The visibility of arts activities, such as performing and visual arts, from the urban environment of the street would be a means to establish a connection between the two. This kind of visibility pertains not only to the pedestrian but to car circulation and the visual experience of the precinct at the scale of the car.

The importance of the urban scale of one's experience is in the way it changes whether one is in a car, or walking. One sees things differently and sees different things; the building as an urban arts centre needs to be identifiable at the different scales to draw the city in.

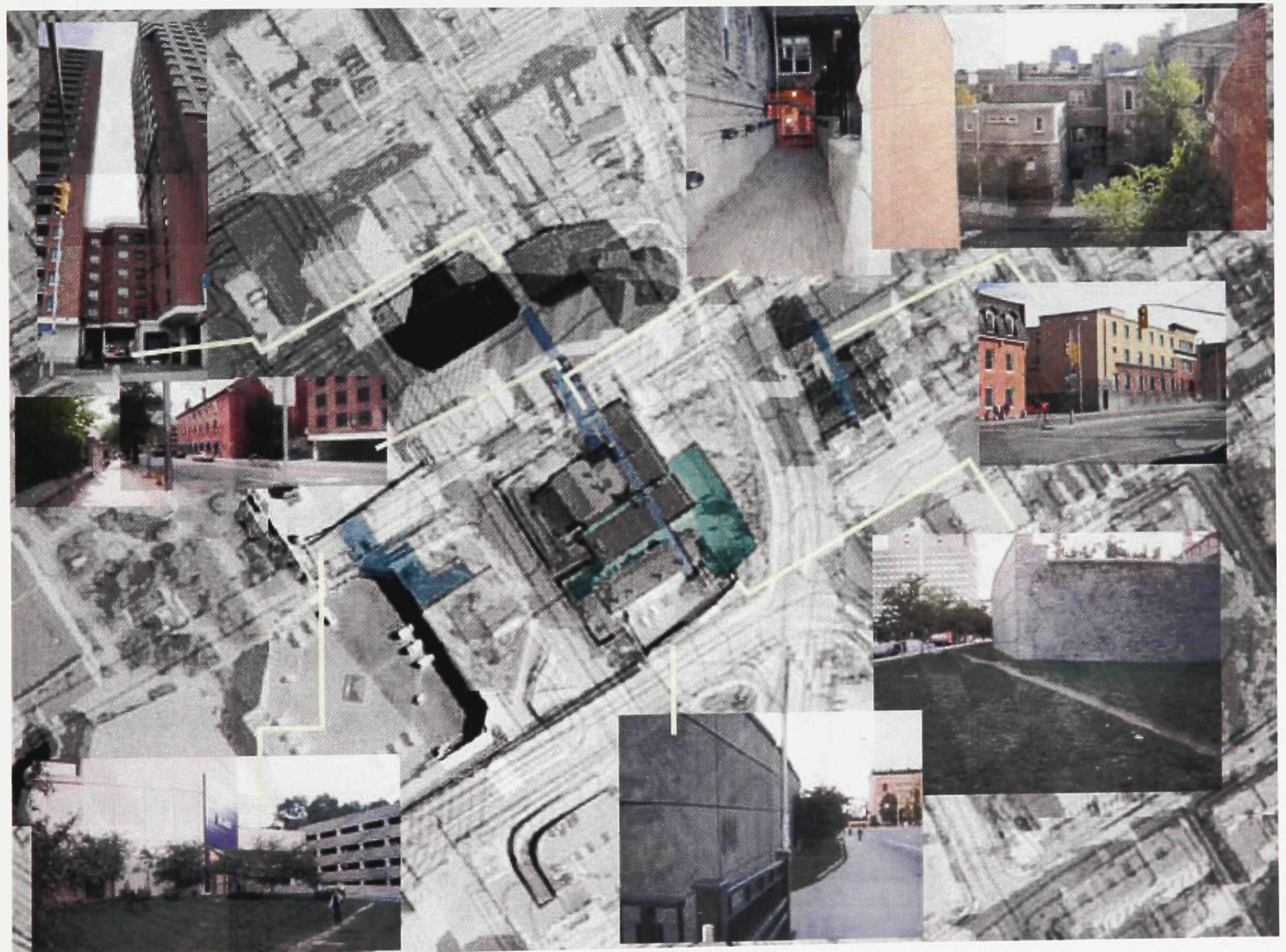

Figure 6 Identification of major urban boundaries.

Underlay from 2003 City of Ottawa topographic maps, GIS Data Catalogue in MADGIC, 2005. 


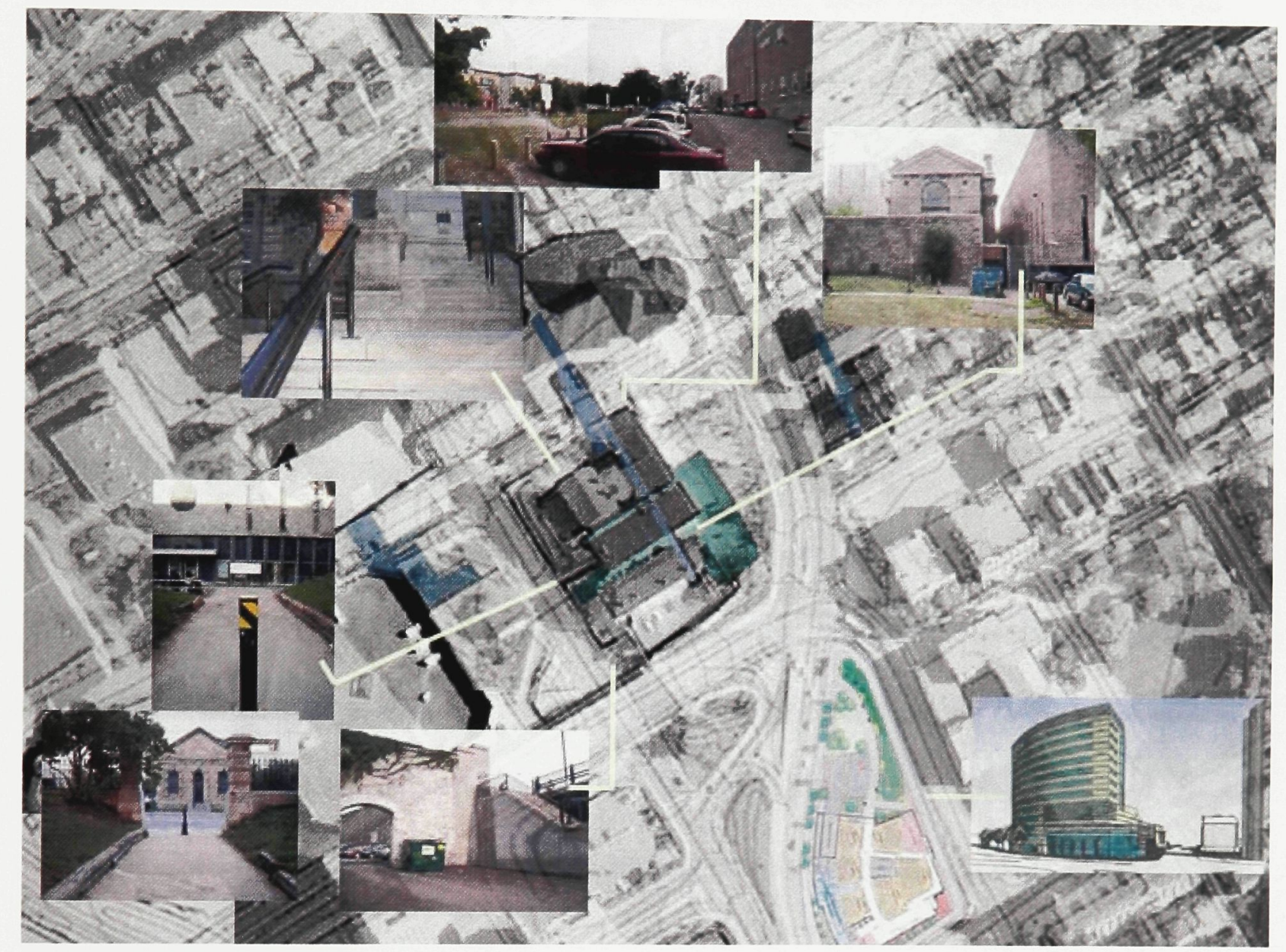

Figure 7 Identification of major boundaries within the site, plus the future Ottawa University Multidisciplinary building (bottom right).

\subsubsection{Refocusing of the Site as a Destination}

When considering the site as a destination, it is important to identify critical points of interest on the site internally and externally, to structurally and spatially engage and redefine existing conditions, with a focus on the experiential qualities of the place. 
Primary destination moments in the scheme are the multiple nodes of access to the precinct. They form approaches from various locations: the University of Ottawa campus across Waller Street, the market further north and from the bus stop at Daly Street, as well as from the Rideau Centre across from Nicholas Street. The Ottawa University approach draws people into the plaza. Apart from these, there are proposed additional separate entrances to the condominium building and to the artist's studios situated along the jail wall.

The most public destination on the site is the auditorium, which is actually nestled in between the pedestrian entrance ramp off Daly Street and a transitional space to the gallery in the new development. This is a pivotal point on the site that integrates the performing arts and embodies the opposing tendencies of the program of the conventional gallery. The auditorium itself has a tight double level seating plan that stresses visual intimacy. The engagement with the auditorium from the surrounding areas would be equally intense, and depending on the direction from which one approaches it, glimpses of backstage happenings are offered. The backstage is a separate object protruding from the auditorium itself.

The final destination moment is the artist studios embedded in the jail wall at the south end of the site. The jail itself is a vital part of the precinct; not necessarily for its historic symbolic presence, but rather because it currently operates as an active youth hostel and contributes to the little animation that does exist in the perception of the community. The ground level of what currently serves as parking would become a seasonal market space 
for the artists in the studios above. As an entity embedded into the wall, the studios act as a visual destination at the scale of the highway traffic.

\subsubsection{Stimulating Multiple Interpretations}

Gilles Deleuze describes the difference between two kinds of writing as they relate to 'expressive' and 'creative' approaches to issues of identity. He makes the argument that majoritorian literature relates to the possibility of artistic practices being reduced to the descriptive. In this mode an image is fixed, normative, and people can write from such a perspective. Conversely, minoritarian literature is against the first form insofar as art has the power for opening and change. For instance, Shakespeare displayed no fixed idea of what the human being is, and as a result had created continuous openings (Deleuze, Guattari 21). In other words, such potential emerges from a lack of a fixed or unified ground, and requires that one writes in a way that searches. This can be related to ways of thinking of the isolated historic site and the perceptions that choose stagnant preservation over its creative potential for the domain it indeed belongs to as an urban artifact: the urban environment. The transformation from the Arts Court to the Arts Precinct resides fundamentally in this move from expressive to creative.

The design within the site can act as a catalyst for complementary actions on neighbouring sites. Circulation through the site can be organized in such a way as to stimulate adjacent building or lot owners to respond in a connective rather than isolating way. Certain speculations are rendered minoritarian in nature, since they are suggestive of new relationships to the city that the public would commonly be unsensitized to. For 
example, one could imagine the campus buildings across Waller Street responding to the Arts Precinct entrance plaza. Similarly, the Novotel might respond to the Arts Precinct by developing the passage to Dalhousie Street as a more pedestrian friendly and commercial pathway. Finally, the Rideau Centre could redevelop the current entrance and façade on Nicholas Street to respond to the 24 hour passage from Nicholas Street to the Ottawa University campus.

\section{Redefinition of the Architectural Boundaries}

\subsection{History of the Building to Date}

The Carleton County Courthouse along with the more recently added component of the police station was converted into a municipal arts centre in 1991. However, it was in 1973 that the need for a municipal arts centre for visual, literary and performing arts was recognized. The City of Ottawa commissioned studies and reports, and support from local artists and citizen groups grew until eleven years later in 1984 when the Ottawa Arts Centre Foundation was established to realize the need for an arts and cultural facility. It would require grants and assistance from governments and public agencies to establish such a centre and support its goals. The Foundation first had to select a site for an arts and cultural facility and the Old Carleton County Courthouse, which was built in 1870, was chosen. The City commissioned a report in the next year concerning the costs for bringing the building up to code for its adaptive reuse. ${ }^{2}$

\footnotetext{
${ }^{2}$ The Arts Court Executive Summary of Feasibility Study, by Ottawa Arts Centre Foundation, Consultant Michael E. Lundholm, May 1990.
} 
Within the following two years its potential as an arts center was explored, and plans developed so that the foundation could assess available financial assistance. The entire program had to be accommodated within the Courthouse as funds were insufficient for a separate construction. Practical issues had ultimately taken precedence over collective goals of the animation of the arts community, yet had not even succeeded at the level of pragmatism. The community's perception of the place and its operations is testament to this.

In addition, the users within the Arts Court have problems communicating and sharing spaces, in part due to the lack of space and funds, resulting in temporary solutions built to minimum standards. The lack of a vision for the entire complex has resulted in little or no emphasis being placed on how all activities engage with one another both internally and externally with the surrounding streets.

At a very basic level, the tenants' needs are not being met. The environmental control systems required to look after the collections of the Ottawa Art Gallery and the technical equipment for presentations by dance, theatre and multi-media companies are inadequate. The current tenants have been working over the years to improve their individual spaces. However, no amount of improvement and upgrading of individual rooms will redefine the boundaries that isolate them from one another, from the public and from the city. As a multi-tenant, multi-disciplinary arts facility that currently houses 25 arts organizations, 
three public galleries and a small black box theatre, it is clear that the upgrading of individual rooms behind the historic walls will no longer suffice.

For these reasons, the Ottawa Arts Court Foundation is now working to create a new Arts Court that will become a cultural precinct in the downtown core of Ottawa. The City of Ottawa has mandated the development of Arts Court and its vacant site into an expanded Cultural Precinct devoted to the arts.

\subsection{Possible Approaches}

Although there exists the desire to create a new arts centre that will address the needs of local professional arts practitioners, those needs cannot be fulfilled without a larger vision for the whole complex. There are many lessons to learn from the previous number of additions and renovations to Arts Court.

The building conservation approach to a historic site would tend to focus on minimizing any impact that a change of program or environmental systems would have on the building's heritage value. This very particular starting point assumes that to alter a building's fabric in any way is to diminish its value, regardless of its relationship to the city, and its status and perception in the community. This tends to be a very restrictive

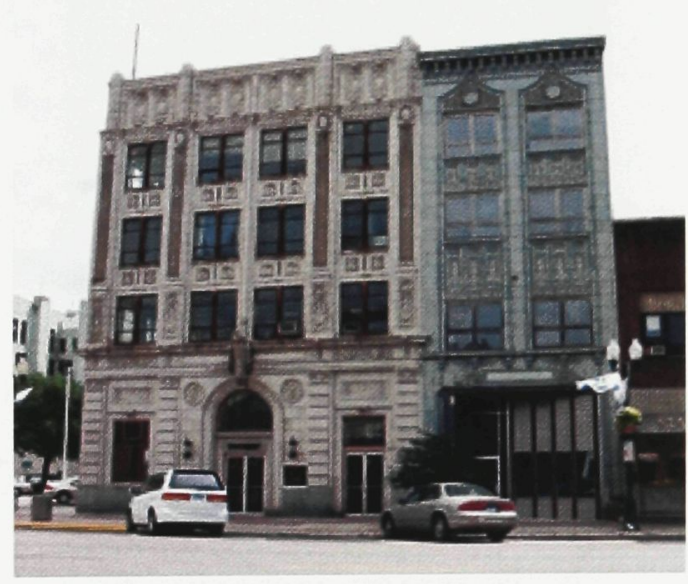

Figure 8. An urban conservation project in Albert Lea, Minnesota. The City may consider its reuse though the extent of the project involves asbestos removal and the restoration of the building envelope, including roof and windows.

$<$ http://www.city.albertlea.org/hpagenda.ht m, 2006>. 
approach with little room for future growth and interpretation. It is inevitable that with a change in context, the meaning of a building will change. In many cases historical relationships no longer have the same relevance; this fact is usually not taken into consideration in such preservation efforts. The extent of the perception is that if a building is not fossilized, it will decay.

Gordon Matta Clark's work can be seen as a clear rejection of such an attitude; trying to operate outside the gallery system, and rejecting the commoditization of art (Atlee, Le Feuvre 16). Although it is more intrusive, this kind of critical approach responds to the prevalent forces that continue to form our cities; those linked specifically to economic determinism, political feasibility, consumerism and image-centered media.

The work of Gordon Matta-Clark forms a bridge between the idea of art and existing buildings in the form of art installations. His approach focuses on the space beneath, through and above architecture by making cuts into the urban landscape. It renders the historic building itself art within the city.

Cutting into a building's structure signifies an approach that probes invasively into the meaning of architecture as urban currency to developers. The act

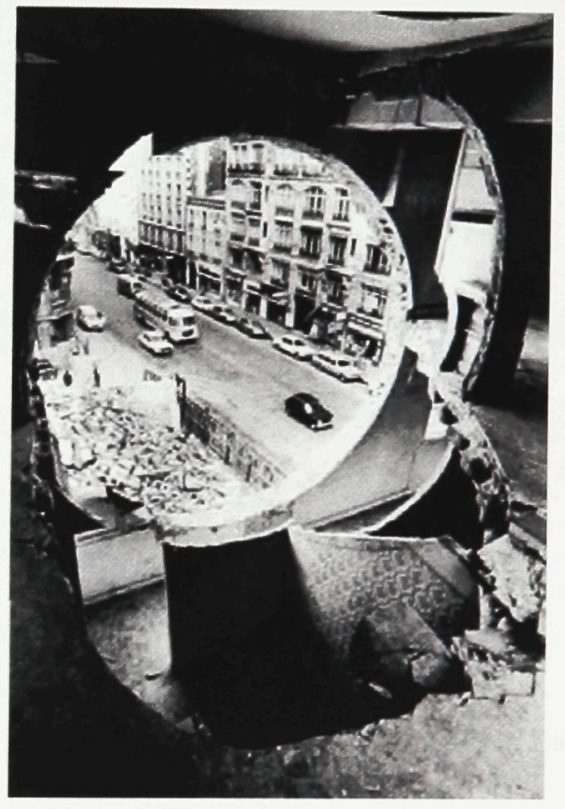

Figure 9. A view through the architectural intervention "Conical Intersect", Paris, Rue Beaubourg, by Gordon Matta-Clark in 1975. Atlee, Le Feuvre, 2003: 58. of piercing the surface of a building can be seen as a liberating gesture and not a destructive one, meant to open up new realms of space and 
understanding. Perforating the skin of a building exposes the structure and contradicts conventions and building codes. Such perforations fill it with something intangible, insert negative space and invert the figure-ground relationship. An approach that makes critical incisions expresses the idea that making a cut through a building's structure may be more respectful of it than fossilizing it through mimetic preservation. Exposing a section of the building's structure can be much more powerful and meaningful in terms of how it is perceived in the city.

In both the case of the conservator and the art critic, the building becomes an art object on display in the city. The difference between the two is the tendency of the former to isolate the site from the city's transformations. The inclination of the latter is to become a part of the ongoing transformations of the city, embodying the living history of the city.

\subsection{Scarpa as Precedent}

The power of architecture is not corrective, but engages things in a positive way. It can reconfigure connections and critically explore relationships. In this sense architecture is the embodiment of complex ideas and must not be reduced to a diagram. The preservation of historic buildings has so often been approached in the literal sense of reuse; one that aims to revive the building's original condition. The language developed by Carlo Scarpa in Castelvecchio represents in my opinion, a thoughtful and appropriate attitude towards the reinhabitation of historic buildings. 
The Castelvecchio project extended over a decade, and although Scarpa had taken on the castle as a major restoration, the full scope of the project was determined not at once, but in stages (Licisco 159). After first being altered in the $19^{\text {th }}$ century for military use, the castle was restored for the second time in 1924 into a museum. Scarpa was first commissioned in 1956 to restore it after it suffered major damage during WWII (Licisco 119). The first phase of work began in the palace's east wing, with the installation of an exhibition in 1958. This

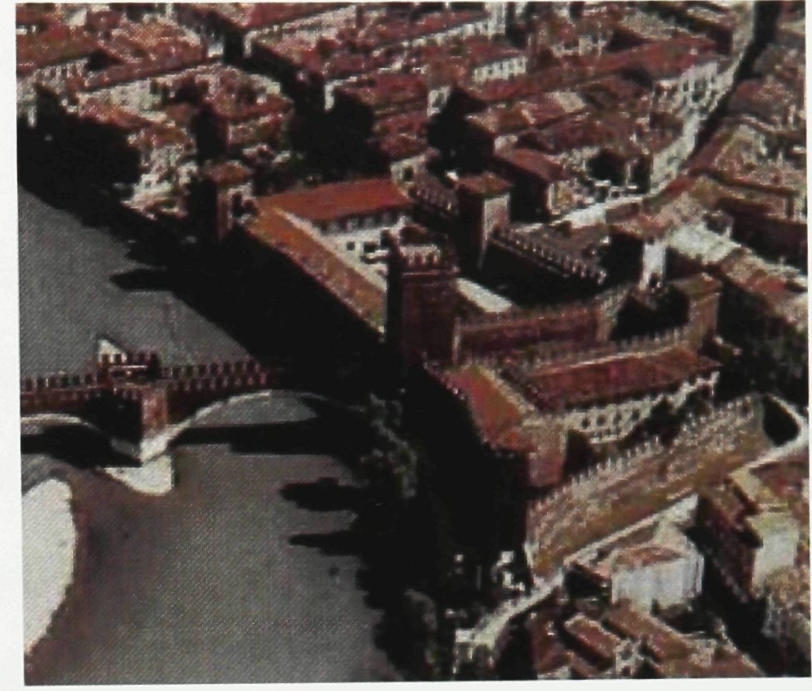

Figure 10. A view of the castle. http://www.comune.verona.it/Castelvecchio/cvsi to/english/storia2.htm, 2006. work also involved the Morbio gate and a connecting passageway that were revealed during excavation. Having initially thought he was only to clear the previous modifications to the castle, work progressed into the gallery courtyard, and the second phase of work began upon completion of the exhibition space in 1961, until 1964 with the inauguration of the museum. The second phase involved the exhibition space, the great court, and the equestrian statue of Cangrande della Scala. The library followed in the next three years, and the final phase of completing the Avena rooms took place in 1973(Licisco 119).

While investigating the nature of the language developed by Scarpa I have made a number of observations as to how the language refelects a reinterpretation of the role of a historic building in the city. The various stages, although developed at different times, reveal his general approach to the existing building. 


\subsubsection{Scarpa's Attitude Towards History}

Embedded within the Castelvecchio are historical layers that were to become Scarpa's medium for intervening with the built structure. A collagist approach of the addition and subtraction of constituent parts enabled Scarpa to develop a visually permeable structure responsive to its urban context. Scarpa's work in the Castelvecchio deviates from the automatic and mimetic response to regenerating the state of a building as a whole. He was concerned with how it could expose the accumulated layers of transformations it had undergone through time. The process he worked through to develop the design reflects his open ended attitude towards history, enabling him to build

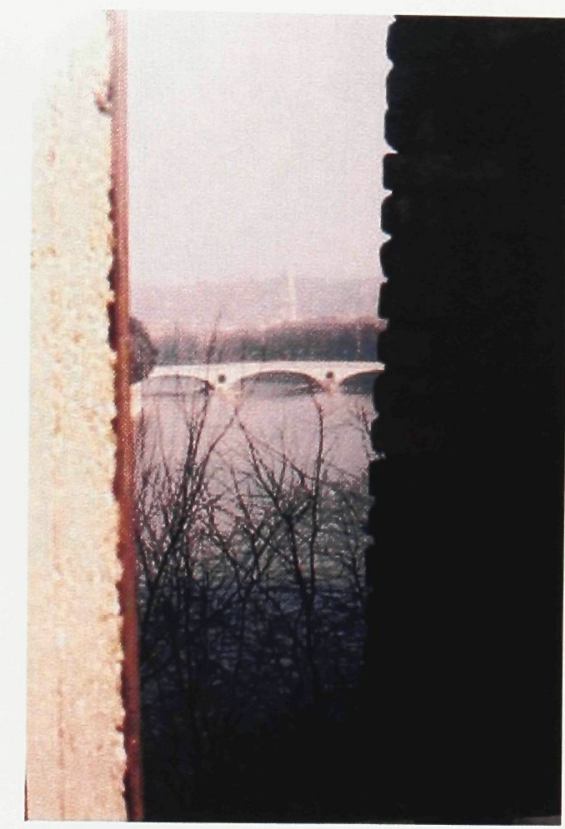

Figure 11. A view to the city of Verona from an essential juncture between interior and exterior space.

Photograph by author, 2003. relationships evocative of their presence as another layer among the rest, positioned for additional intervention. His belief in the continuity of history is embodied within his treatment of art as a way for tradition to reform.

Specifically, his approach to the historic fabric involved exposing the castle's historical layers by uncovering parts of the existing structure's walls and roof to its interior and exterior spaces. In an additive and subtractive manner, secondary wall planes and screens were added at essential junctures at the entrance, in the passages between chambers and at windows. The subtraction in his intervention occurred with the 
separation of the two main buildings to reveal the intersection of their foundations. ${ }^{3}$ The intervention becomes multiplicitous in language and scale, inherent at the level of connections within a detail.



Figure 12. View of multiple planes at windows as the threshold between the historic structure and interior space of the exhibit.

Photograph by author, 2003.

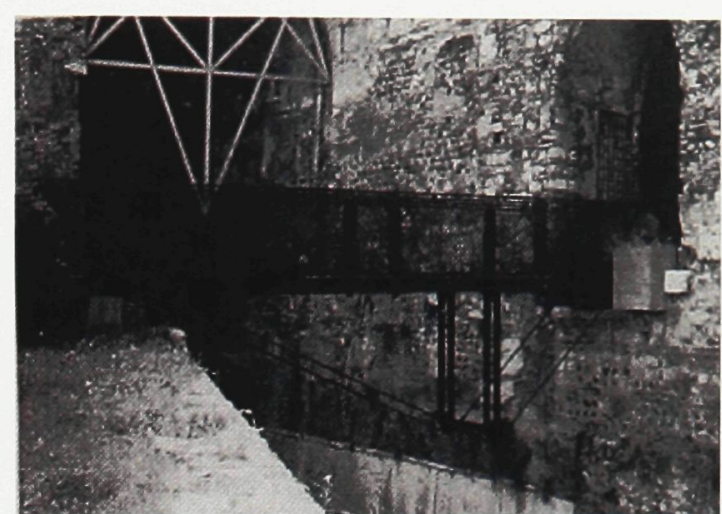

Figure 13. View of a bridge that crosses exposed layers of the original foundations.

Albertini. Bagnoli. 1988: 64.

\subsubsection{Amplification}

In the Castelvecchio, Scarpa amplifies the relationship between the viewer and how a work is engaged by making the existing structure a critical mediator between the two. Rather than commonly displaying works of art objectively against a blank wall, the works are singled out as entities unto themselves but distinguished by the armatures of plaster, wood and brass on which they are presented. The works of art

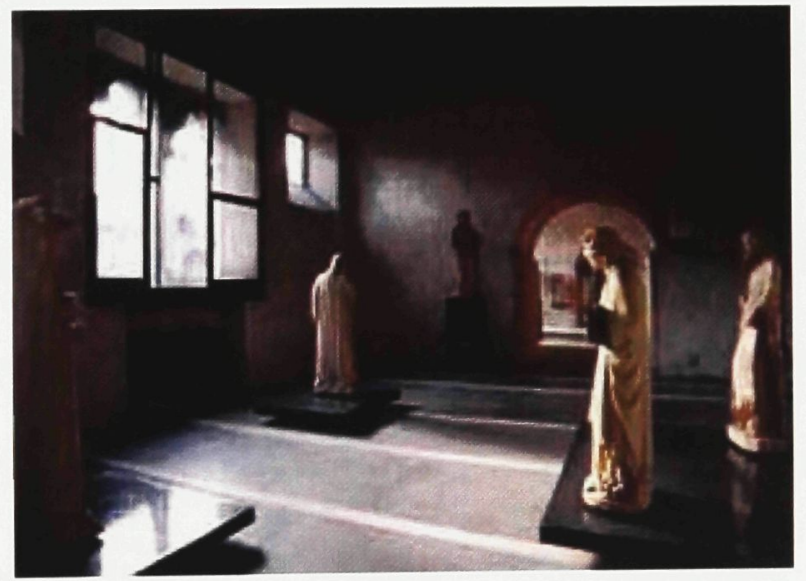

Figure 14 . View of gallery space and exhibit installations upon which works are displayed. http://www.comune.verona.it/Castelvecchio/cvs ito/english/collez2.htm, 2006.

\footnotetext{
${ }^{3}$ Giovannini, Joseph. "History's Architect" in Art in America, New York: Brant Publications Inc, Oct 1999. Accessed via http://www.findarticles.com/p/articles/mi_m1248/is_10_87/ai_56906446/pg_1
} 
are distinguished in such as way as to waver among exhibit pieces and components of the building iself. They also fluctuate between belonging to parts of the building and parts of the exhibit, thus merging art and architecture, in additional ways. One involves the disintegration of the scale of the building to the works of art. The other involves the treatment of light as an intermediary between art work and the building, not isolating the treatment of either but washing both with daylight. ${ }^{4}$ Approaching the works from different directions is ensured by their ultimate release from the realm of the wall.

Implications for the Arts Precinct

The relationship between how art is displayed and experienced in the Arts Precinct

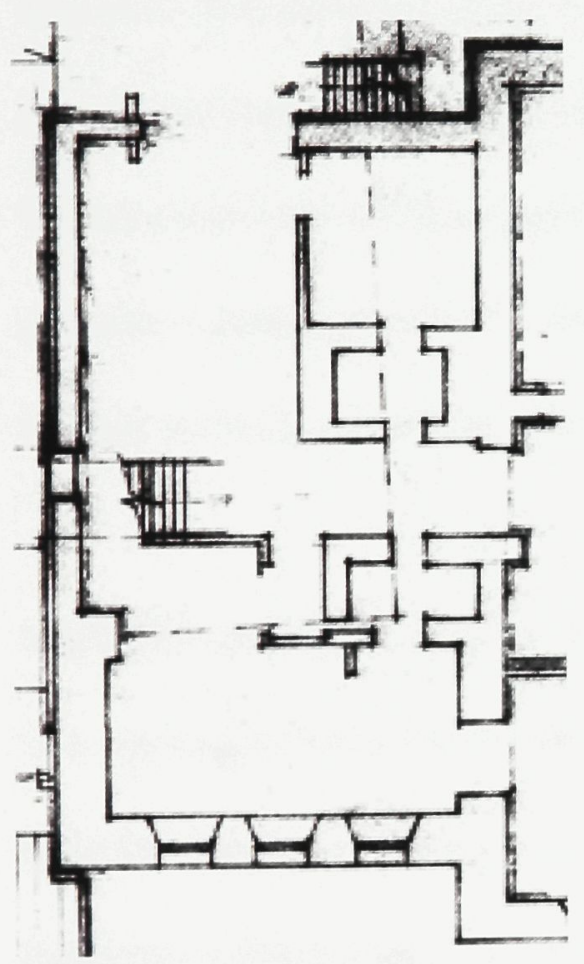

Figure 15. Display interstices on ground floor of Courthouse. Image by author, 2006. proposal is amplified in the studio gallery space associated with the Courthouse. Display niches are formed out of existing walls on the ground level for the exhibit of sculptures and other objects, in various arrangements according to how an artist wishes for them to be encountered. The studio spaces above correlate to the orientation of the niches themselves; in a different way than in the Castelvecchio, this relates the scale of the building to the works displayed. In addition, this contrasts the way in which works are displayed by the traditional gallery program. As a foil to such an approach, the latter can be seen in the gallery of the new development,

\footnotetext{
${ }^{4}$ Giovannini, Joseph. "History's Architect” in Art in America, New York: Brant Publications Inc, Oct 1999.
} 
associated with the more dominant curatorial aspect. This element involves the control over what, and how the viewer sees; through, for example, the frame of a chosen portrait.

\subsubsection{Redefinition of the Role of the Wall}

While the existing walls remain more or less intact in the Castelvecchio, it is striking that the experience of the Museum is not one of moving from room to room. Instead, the walls activate movement by engaging edge conditions. More specifically, this is articulated in the way one follows a spatial sequence that unravels along exterior public spaces and interior gallery exhibits.

Visitors follow a winding path that enables multiple vantage points of a destination,

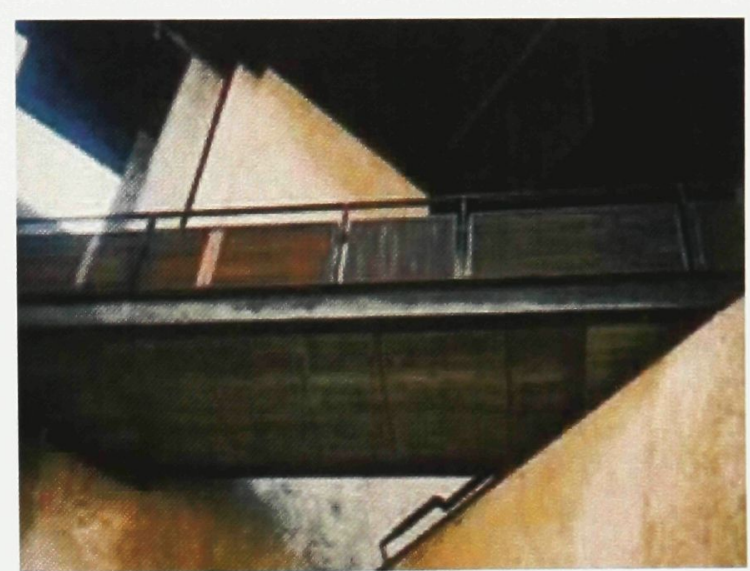

Figure 16. Elusive of walls: view to a path engaging threshold conditions of interior and exterior spaces.

http://www.comune.verona.it/castelvecchio/cvs ito/english/scarpa8.htm, 2005.

instead of being set out as a linearly ordered pathway.

Implications for the Arts Precinct

It is critical to resist the conception of space that it is conceived of in the confines of walls and the avoidance of 'mass' to which program is designated. Instead walls can be used to investigate how movement, the space of circulation, can form relationships. This enables, for example, the kind of sensibility that draws in the pedestrian and brings artistic production as part of its

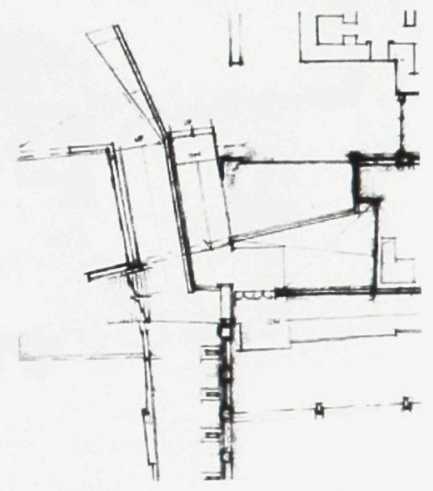

Figure 17. South-East approach into the building. Image by author, 2006. 
internal operations, out to the city. The entrance that forms the Ottawa University approach, for example, is pushed out of the corner of the building in a charged moment that faces the rest of the site. This new boundary activates the residual corner that originally hid the theatre studio which was almost completely inaccessible. The path traverses both sides of the wall, remaining as an exterior ramp in the interior of the building, until a set of doors are reached deeper within the building where it is resolved.

Infiltrating the building's walls with inhabitable spaces in specific locations has allowed visual permeability of the site from the highway, the Mackenzie King Bridge, and to the pedestrian. It suggests new possibilities for engaging the disjointedness of interior and exterior spaces of the

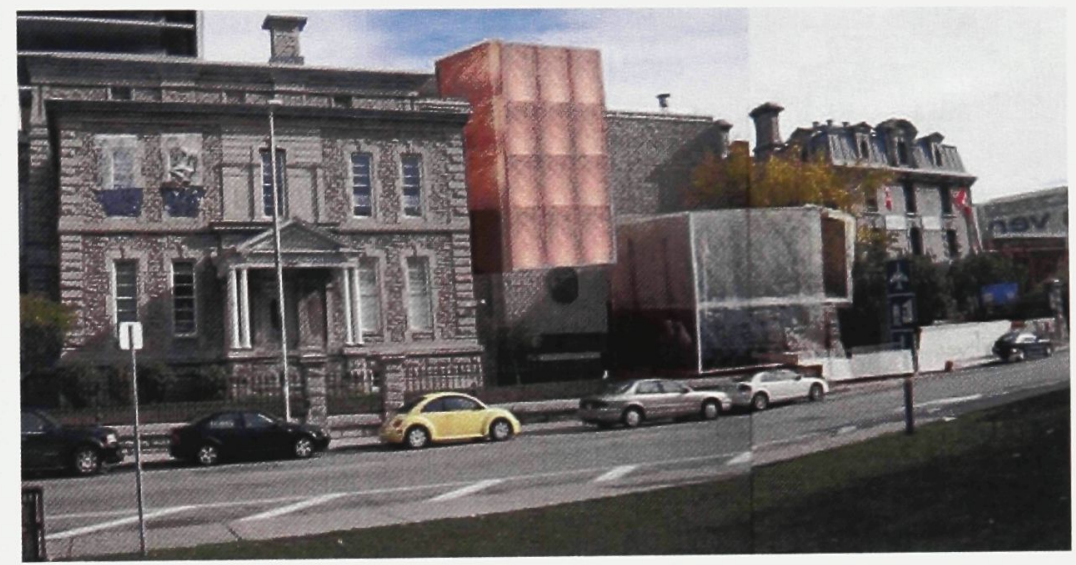

Figure 18. West elevation (resource centre in copper wall panels).

Image by author, 2006.

building. For instance, the studio spaces in the courthouse associated with the proposed art school make a direct transition into a resource centre that is accessible to and brings all disciplines to use it. The resource centre is however, nestled in a part of the exterior space of the courthouse, as a structure that reevaluates the two

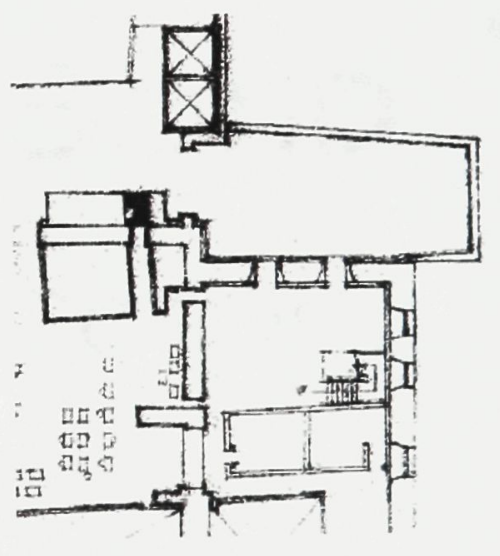

Figure 19. Transition to resource centre. Image by author, 2006. 
conditions demarcated by the threshold of the wall.

\subsubsection{Architecture as Narrative}

In some instances at the Castelvecchio, the artifacts articulate the links between old and new. The spatial configuration is strongly connected to both the visual memory and the

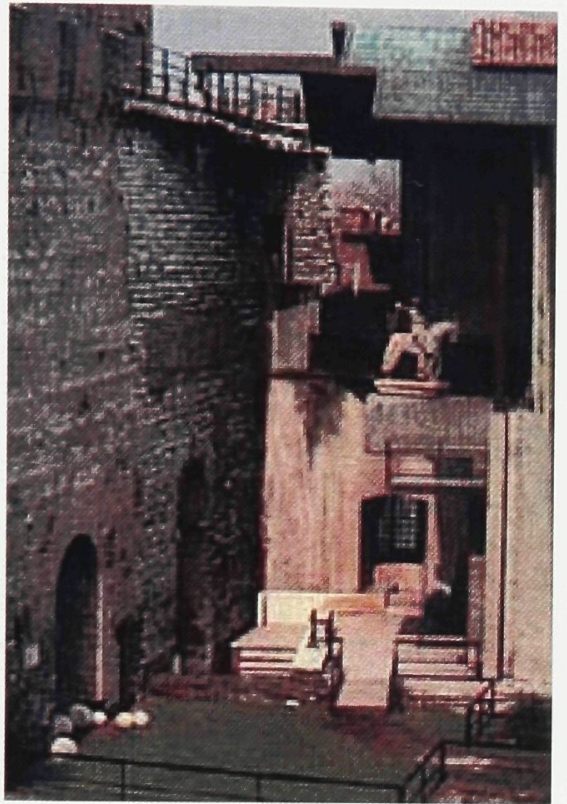

Figure 20. View of the statue. (In relation to figure 22 and 23 )

Multiple views of one's destination as a display is approached.

http://www.studiocleo.com/gall erie/scarpa/castelvecchiomusma anticipation of the viewer as narrator in his/her

surroundings. The clearest example is at the spatial intersection of the exterior public spaces and interior gallery exhibits, to accomodate the Cangrande della Scala, an equestrian statue of a Veronese nobleman. Surrounded by a staircase, this figure is the pivotal point of the visitor's movement through the museum, as it stands at a precipice between the buildings to expose a historical link in all directions.

\section{Although points of}

arrival and destination

are intentionally not clearly established, the event of the statue is arrived at through a spatial narrative of

walkways that unravel and fluctuate between the interior and exterior of the building. Instead of being set out as linearly ordered pathways, the sequence of moments that lead up to its encounter begins in the courtyard with the

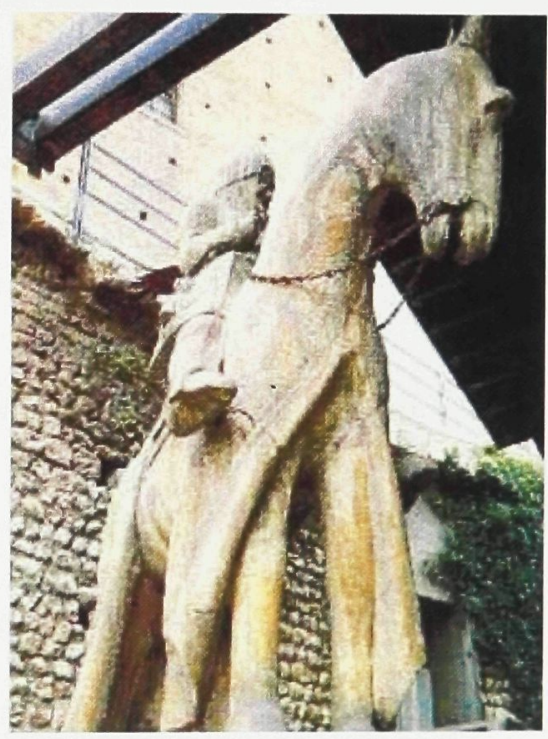

Figure 21. Cangrande della Scala. http://www.studiocleo.com/gall erie/scarpa/castelvecchiomusma in.html, 2005 
opening of the ancient moat, which is traversed by a bridge above shallow pools of water. One is led through the various exhibits along a circuitous path that continuously brings the Cangrande into view from different positions both above and below (Licisco 118). The visual memory with which Scarpa embodies his work is key to the visitor's experience of the museum.

The Castelvecchio breaks from traditional museum design in terms of movement through the spaces. The discontinuous spatial relationships relate to the articulation of historical divisions of the museum, revealed among separate nodes by breaking the museum circuit. Historically, the vertical circulation met at the far

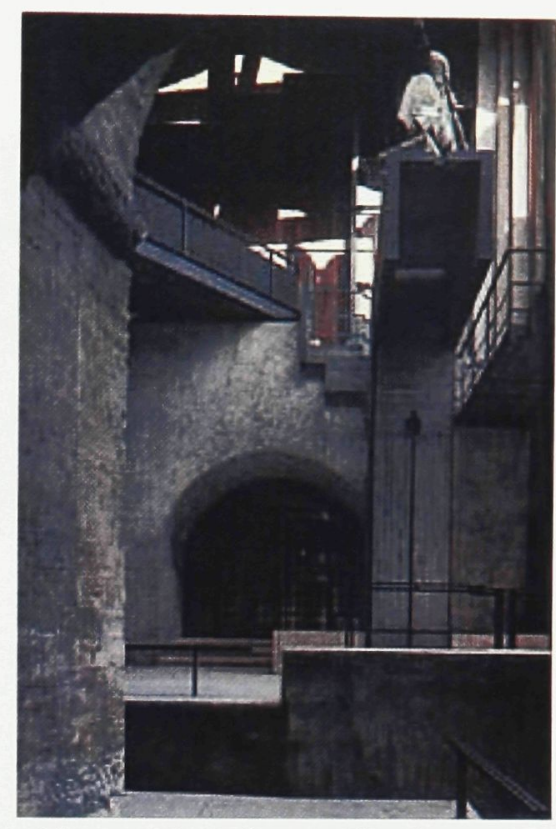

Figure 22. Release of pathways into space of display.

http://www.studiocleo.com/gall erie/scarpa/castelvecchiomusma in.html, 2005.

end of the museum; it had been reconfigured as the center, by having removed accumulations from the $19^{\text {th }}$ Century in that region and clearing the moat. The circulation becomes an integral part of the exhibition program of the Museum.

Implications for the Arts Precinct

The Arts Precinct proposal responds in a similar fashion with the configuration of the main circulation. It traverses the building from one end to another from which the various program of the theatre complex and art school can be accessed through a bilateral connection. The accessibility is interwoven in the way one continuously reverts to this central circulation space from different points. To establish such a clearing required 
removing the more recently concealed original fenestration of the courthouse on the interior. The recovery of certain elements that were concealed by perhaps unthoughtful additions can reinforce programmatic links, visually or physically.

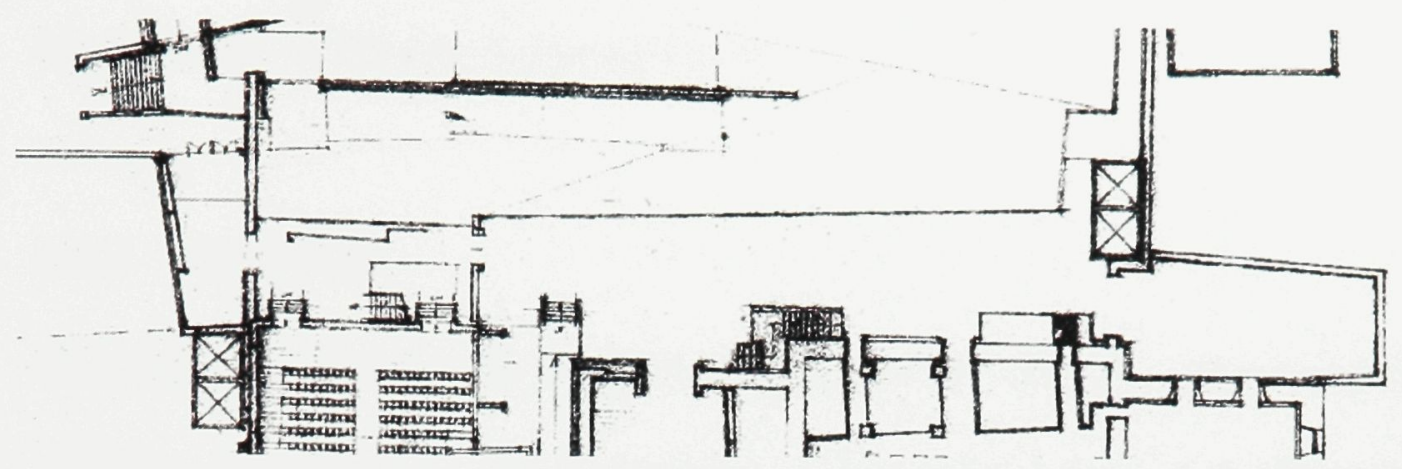

Figure 23. Main circulation on second floor.

Image by author, 2006.

Another instance of this in the Castelvecchio is where the northeast tower at the opposite end is emphasized by the opening made by the library and Avena room, which recover apertures at the opposite end during the Napoleonic period. ${ }^{5}$

A primary layer to Scarpa's work is his investigation of the progression made by the historical structure. The studies are based on defining elements either by emphasis upon revealing each other, or in opposition to each other (Licisco 159). In terms of the existing buildings at the proposed Arts Precinct, this idea continuously affects the conditions under which programmatic relationships are built.

A building such as the Castelvecchio reinforces the notion that a building can be positioned for further intervention and can be open to continuous modification; similarily to the continuous transformations cities undergo, but at a different scale. The end of

\footnotetext{
${ }^{5}$ Magagnato, Licisco. "The Castelvecchio Museum" in Carlo Scarpa, Milano: Electa Editrice, 1984, p.118.
} 
construction should not announce the completion of a building. A 'live' architecture is one which has the potential to continue to respond as an urban artifact, to new contexts, and histories as narratives. This potential is inhibited by restricted perceptions of what the development of the city is planned to be.

\subsubsection{The Detail}

The shift in Scarpa's work from traditional museum design extends to his design of exhibition installations. His fragments in Castelvecchio engage and become part of the works of art themselves, as a whole composition. They unfold around the works as a "visual commentary". 6 In addition to the numerous displays, this sensibility can also be seen with the highly intricate insertion of the figure of Cangrande della Scala, which also reveals Scarpa's mastery of bringing together different materials. It was in this museum that he felt "the symbolic potential of facets of his compositions", through "the integration of water and the effects of chiaroscuro". ${ }^{8}$ It should be noted that Scarpa's concern with detail and materiality are mediated through the

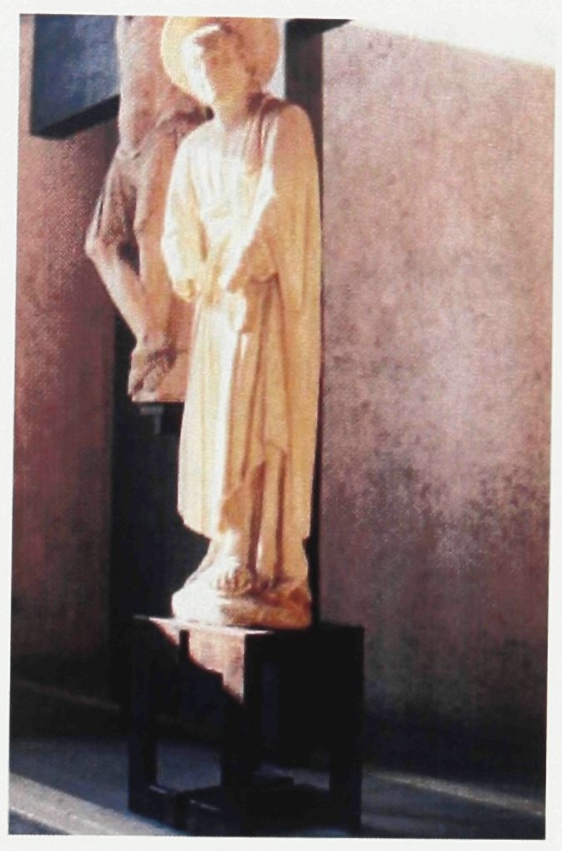

Figure 24. View of exhibition installation as armature for display.

Photograph by author, 2003.

\footnotetext{
${ }^{6}$ Dal Co, Francesco. Carlo Scarpa, Milano: Electa Editrice, 1984, p. 32.

${ }^{7}$ Francesco dal Co explains the sense in which Scarpa's compositional elements may become symbolic: "symbolical' in the topological sense of the term, derived from 'sumba/lein', meaning 'to combine' or 'fuse together' ".

${ }^{8}$ Dal Co, Francesco. Carlo Scarpa, Milano: Electa Editrice, 1984, p. 53.
} 
construction and reconstruction of narratives at two scales: one of the spatial sequence through which one moves through the museum, and that of the architectonic narrative of the fragment into which one's embodiment of it is projected. ${ }^{9}$

\section{Implications for the Arts Precinct}

Scarpa's sensitivity to the detail and the relationship to one's immediate surroundings inspired a moment in the Arts Precinct proposal where boundaries are blurred through a celebration of a threshold with water. The narrow space between the Courthouse and hostel is an inhabited space, whose roof collects water.

The water is then directed around the corner of the building onto a surface in another space, which lies between an insertion of new construction and the exterior wall of the Courthouse. The new construction houses a

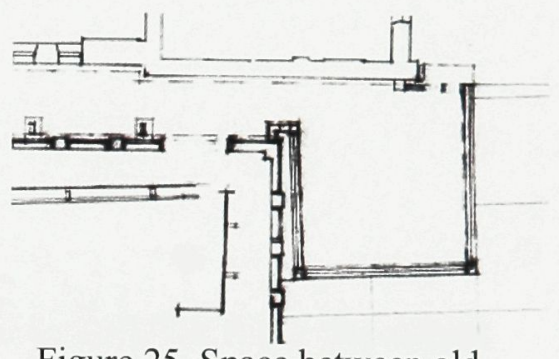

Figure 25. Space between old and new fabric.

Image by author, 2006. dance studio that allows a level of visibility of movement to the street, while it creates layers of visibility to the interior of the building. A wall of water is viewed through the stone wall's vertical openings, suggesting multiple elusive boundaries, an embodiment of an essential question of the role of a boundary itself. Though a boundary is regulatory, there is nothing damaging in a boundary itself. It is the conditions of that boundary, or what is being separated, that needs to be addressed and in many cases redefined. The relationship between the historic wall and the space of the new dance studio to the exterior of the wall is articulated in glimpses through layers of stone, glass and water, of dancers' motions, unraveling in the very threshold of the

\footnotetext{
${ }^{9}$ Scarpa's compositions bring together composite materials. Of these he treats natural elements such as light and water as spatial elements. That building is manifest of thought is something that reinforces the manifestation of form through sight and it is this fixed moment between a form and sight of it that enables it to resist both defy time and habit.
} 
boundary itself. Tangible and intangible boundaries here are reciprocal. The way in which a person engages a work is on one level bound by the physical boundaries between the two. Yet, the social and perceptual boundaries between the world of the artist and world of the viewer are defined by the spaces which they inhabit. Those spaces in turn reflect the conception of the relationships between the two; their redefinition lies in the configuration of the architecture that embodies their activities. As art works, in light of the 'death' of art, are meaningful in relation to the distortion of their subject, the spatial canvas of the precinct thrives on the twisting of the existing structure as its basis for configuration.

\subsubsection{General Implications for the Arts Precinct}

In the Arts Precinct proposal, the focus is on reorienting the pedestrian from the urban realm into and through the realm of artistic production. From the perspective of the artist, the intention is to enable artistic production of different disciplines to occur in the midst of one another. The organizational component of the project can be better understood by observing that of the

Castelvecchio, in which the overall configuration of the insertion culminates at the exposure of an art work, the Cangrande; in the proposed Arts precinct the spatial configuration culminates at an urban filter, the

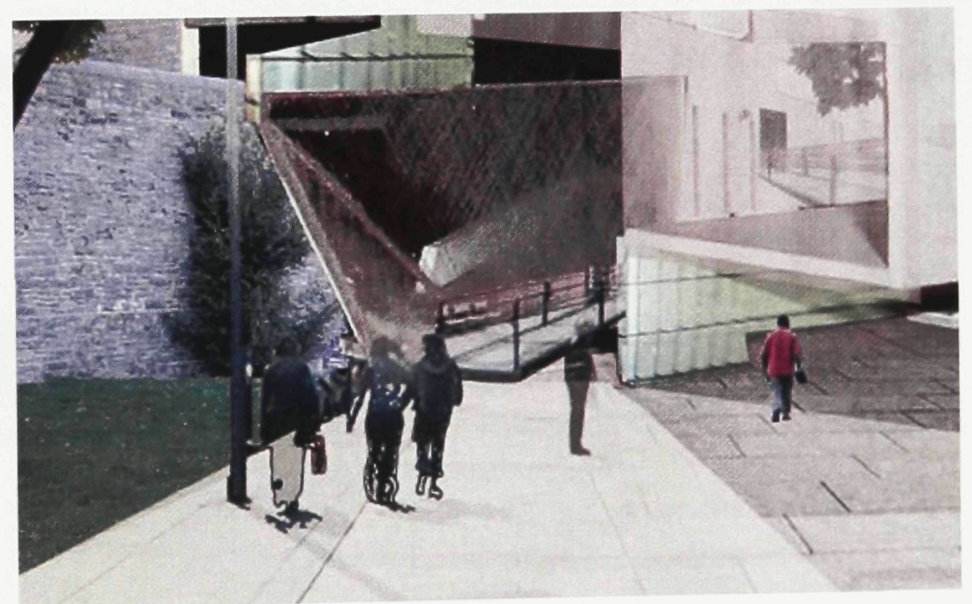

Figure 26. Movement through the building from various entrance nodes culminates at a South-East approach to the precinct.

Image by author, 2006. 
threshold and main hub of activity, from which movement disperses in two directions, north-south and east-west.

The north-south connection is a ramp that passes through from the exterior of the building and becomes a public exhibit element that is interwoven to allow the public to be witness to the work happening in adjacent spaces. One can think of two urban realms, the first being the exterior surroundings, and the second, the enclosed realm of artistic activity. The boundaries between the two, which were originally demarcated by the tough and impenetrable historic walls, have been redefined. People can wander into this spatial canvas and back out: the building filters movement in such a way as to make art works part of the public realm to the extent that it can be visually but not necessarily physically accessible to everyone.

The east-west connection fluctuates between the space on either side of the wall facing the jail; essentially it is the space between the jail and Arts Court that breaks into and out of the wall of the building. As a continuation of the entrance and public space, it forms a 24-hour passage that allows glimpses into studios and theatre activity such as performances and rehearsals.

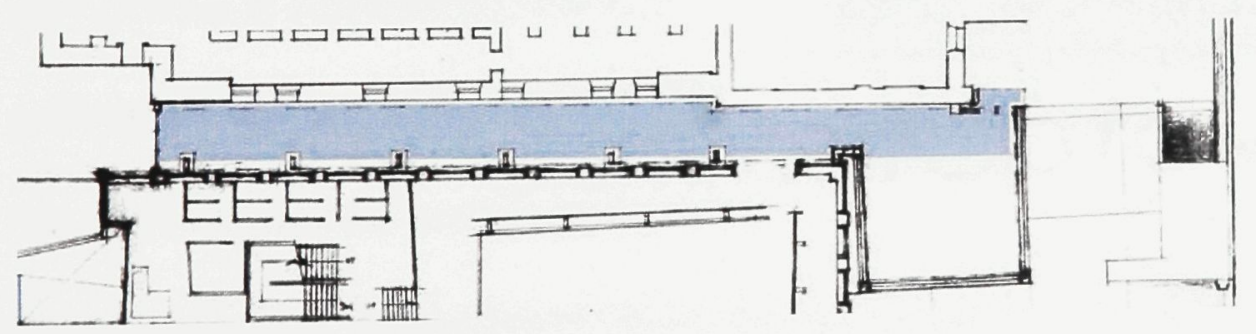

Figure 27. 24-hour passage leads to a café facing Nicolas Street. Image by author, 2006. 
The many institutions that are a part of the Arts Court can form the Arts Precinct by agreeing to participate in a larger administrative unit. The exhibit elements and larger support spaces such as studios and workspaces are interwoven; yet each operates independently with its own circulation, entrance and reception. This contributes to the sense of the immersion of the exhibiting activity into the realm of artistic production.

In the proposed Arts Precinct, the relationships between the display of art in its 'final' form, and artistic production, are essentially the framework for integrating the new and historic fabric. Specifically, they are developed through the performing and visual arts with their respective exhibit counterparts. The theatre complex for the performing arts includes a theatre studio, impromptu theatrical space(specially designated to various activities), dance studios and and a 200 seat auditorium. The visual and media arts are associated with studios, classrooms and student gallery space in the arts school along with artist studios located at a different part of the site outside the historic walls of the courthouse. The ground floor of these studios occupies part of what is currently the hostel's parking lot and are not in fact studios,

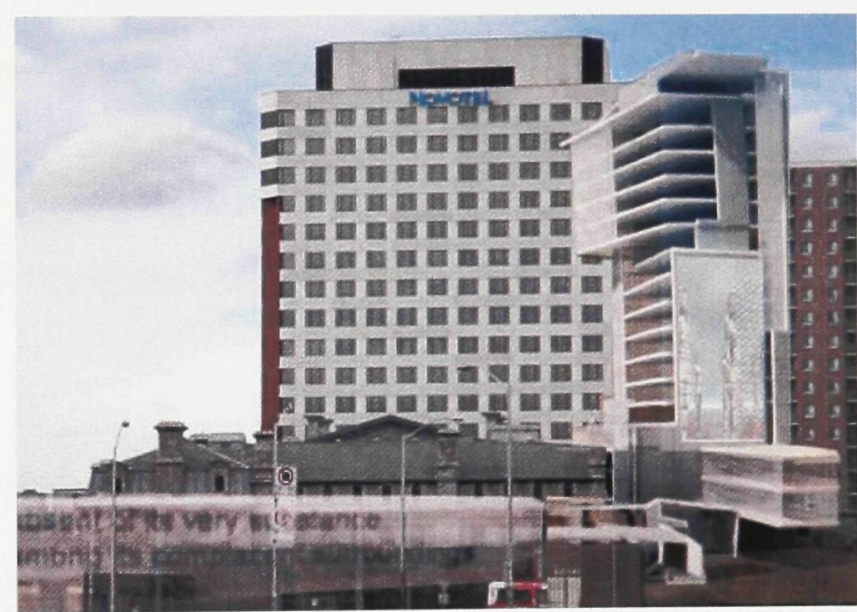

Figure 28. Artists' studios along jail wall. Condominium building on right.

Image by author, 2006 . but serve as seasonal market space for artists while their studios hover above and are embedded into the jail wall. 
The original entrance to the courthouse had a security wall to prevent riots after unfavorable court hearings. In response to the change of program to a municipal arts centre the stairs to the entrance were redone and presently ascend from three sides towards the main doors. With the new proposal for the Arts Precinct, this element must once again be reevaluated.

To reinforce the idea that this is a precinct and not a building, a new and much more public entrance that feeds the interstitial spaces of the project and better aligns with the adjacent laneway configuration is introduced. The original courthouse entrance is made into a balcony space that is only accessible from the inside and becomes a space of public debate. This would seem to be a fitting

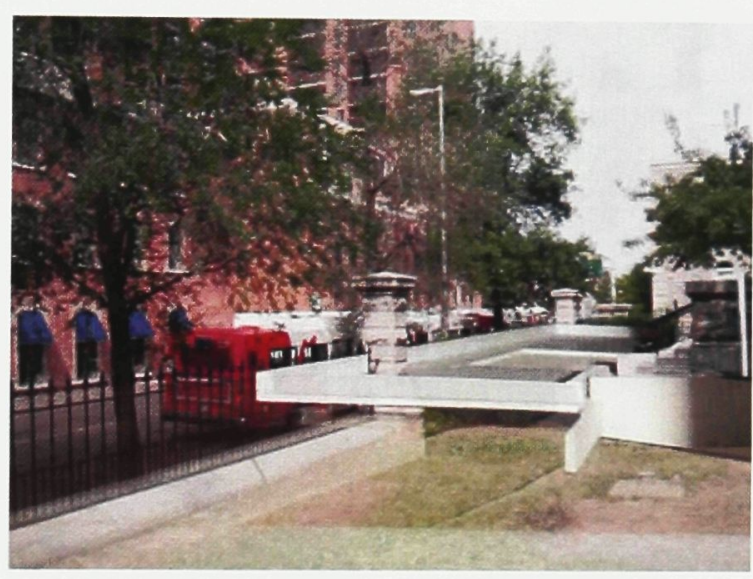

Figure 29. Balcony space. Image by author, 2005. reinterpretation of the original preventative measures for public display.

Other attempts to engage the public have been addressed in terms of program, the connections to surrounding patterns of movement and developments, increased visibility both internally (pedestrian circulation) and externally (car circulation), street presence to the public, ground floor access to performance and exhibition venues, or indirect public access to certain exhibits. 
In terms of program for example, the entrance facing Waller, which is pushed out of the corner of what was the police station, welcomes the public into the main reception, from which it may continue to the auditorium or to a secondary information desk to further direct people to the arts school, gallery or the rest of the theatre complex. Ground floor access to various venues is achieved through such ramps. Conversely, the same reception is reached from the north-south ramp that gently slopes up from the sidewalk as a continuous yet subtle divergence from it and links surrounding patterns of movement. It is reached after encountering pivoting exhibit walls whose displays change according to arts program schedules. Other attempts to engage the public through links

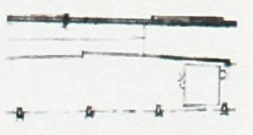

between patterns of movement are on a portion of the site where the residences help define a plaza as part of the public realm. It is here that there is an increasing slippage between its structure and envelope to lift off the ground and open itself to the public.This engages

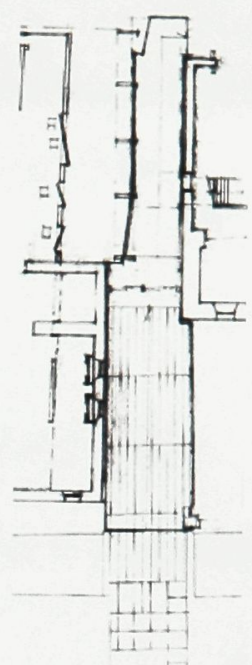

Figure 30. Market approach to the Precinct from the North.

Image by author, 2006. movement in the boundary between the two, on the exterior of the building as part of the language of the plaza. A transition is made from what is a more enclosed structure facing Daly to a more active public realm.

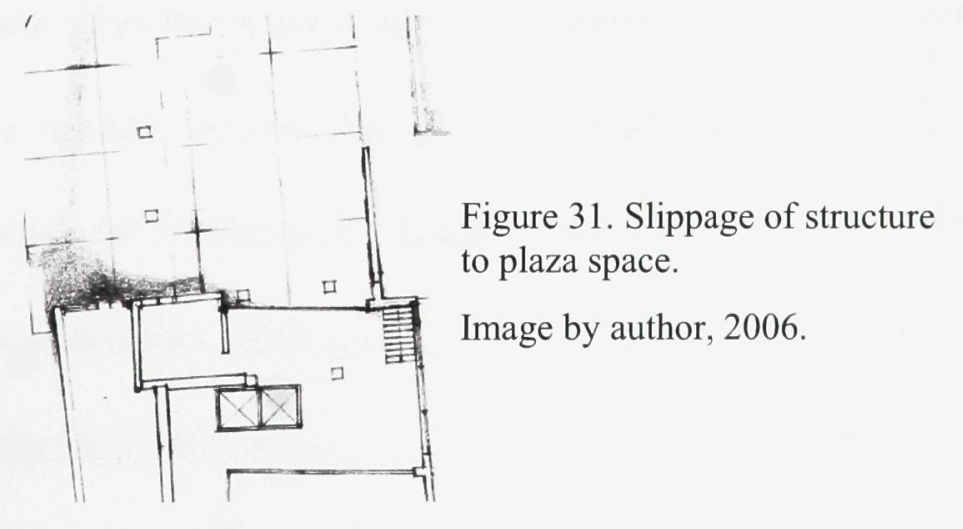


By virtue of establishing an organizational strategy that is central to circulation and

filtering movement through the

building to its surroundings, the

public will also be engaged

because of the plethora of visual

links internally but also at different

scales. There are two media

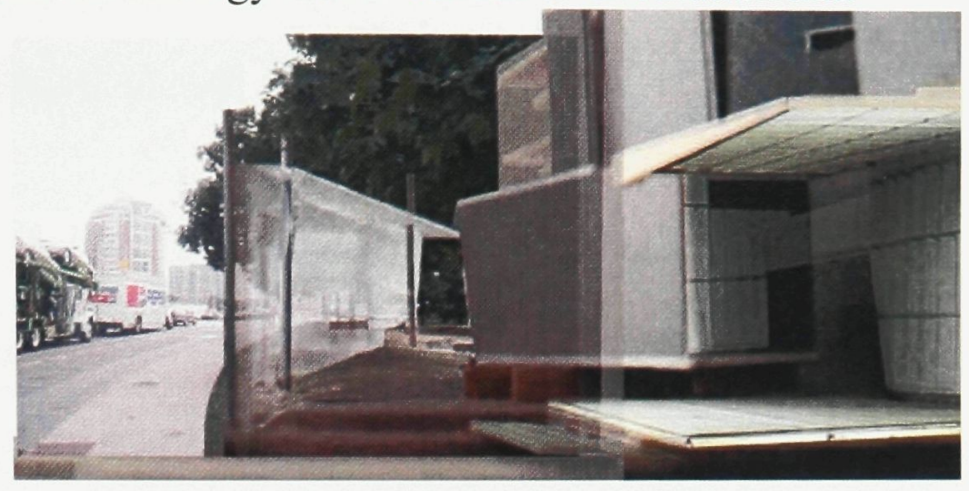

Figure 32. Screen defined as a boundary along Waller alongside a separate Gallery entrance.

Imgae by author, 2006.

screens, one is a wall of the

condominium tower addressing the highway, and the other is a boundary along Waller.

The second one operates twofold: the noise levels due to trucks along Waller is extremely high, and would not welcome the public into the plaza as public space.

Redefining the boundary to blur the sidewalk from the side periphery while simultaneously placing a barrier more appropriately defines the conditions of the plaza space. The sidewalk is blurred from the site edge by a street paving pattern that crosses the street to the University campus, with street lights integrated into the barrier itself.

Various architectural boundaries are informed to some extent by redefining urban boundaries. This has a great impact on attempts to engage the public, as many aspects become highly interconnected. Pedestrian circulation through the building is initiated as an urban

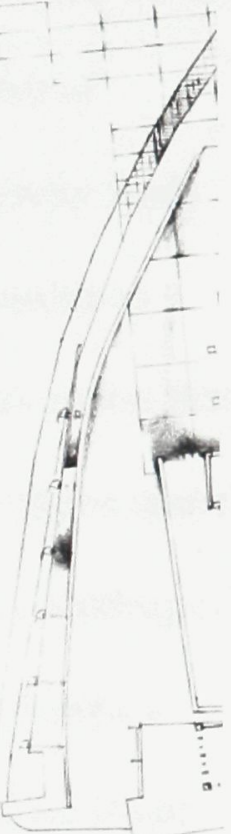

Figure $3 \overline{3}$. Site periphery along Waller Street. Image by author, 2006. gesture but informs the programmatic links as well. Individual organizations are promoted while maintaining their integration with one another. The main circulation 
element traversing the building is an example of how such interaction is encouraged. Also, access to the elevator and loading dock will be directly visible to performance venues and exhibition facilities.

Precedents may help further one's understanding of the importance of one's movement through the precinct. It is clear that in integrating new structures with the structures of the castle, Scarpa celebrates the differentiation between the two to the extent that there is no sense of a totalizing entity that structures the field of fragments or creates a spatial sequence. The configurations of the spatial constructs are moments that stand as thresholds between pause and event, depending on the movement of the viewer through the space. This is for the reason that each moment, 'room', configuration, or construction, is elusive of any fixed point of reference or origin. Instead, if one can conceive of replacing a fixed point of reference with the idea that the body's centre of gravity lends itself to the space it is in, a new centre of gravity forms through one's relationship to one's surroundings and thus through one's movement through the space. This means that one continuously adapts to the space one is in, in the absence of the linearity that a space with a fixed point of reference would have. The point of reference is instead a shifting one, embodied in one's projection into the space through which one moves. Scarpa's constructed 'moments' amplify this relationship by disintegrating the traditional linear sequence of the museum by offsetting the spatial configurations with new connections that continuously unfold along the viewer's path. In contrast, there would be a detachment from the body in a 'static' space oriented to a grid. This typically results in dead, 'designated' public spaces and in spaces which are mostly seen for having their 
qualitative aspects in the objects and accessories within them. The proposed precinct confronts such situations by engaging the historic complex.

\section{Redefinition of the Boundaries found within Art Discourse}

\subsection{Introduction}

The creation of critical frameworks in art discourse can be enhanced by creating an architecture that 1 . enables interaction between artists of different media, 2. focuses on the common processes that their works go through, 3. defines and expresses clearly what is deemed to be educational space versus operational space, and 4. enhances the awareness of the viewers with respect to how they relate to and experience art works. Existing impediments in these areas can be traced to both the realm of the artist and that of the viewer. In the artist's sphere, barriers traditionally exist between artists of different disciplines; the painting room, the sculpture room, the photo studio, the theatre rehearsal room etc. end up being rooms off of corridors with little or no physical or even visual connection between them.

In his discussion of the end of modernity, Gianni Vattimo challenges the traditional definition of art. He explains the truth of art to be in the experience of it. Arts works, as post modern gestures, embody meaning in relation to what preconceptions they serve to distort (Vattimo xxix). The intention of the thesis project is to challenge the institutionalized conception of art that tends to undermine the public nature of the program, and instead articulate relationships that emphasize the arts precinct as an active 
place of artistic production. Strategies used to challenge the traditional gallery program are outlined below.

The gallery aspect of the program is dispersed; certain gallery spaces are located in the new development outside the existing buildings, associated with the permanent and existing collection. Other more active program components associated with workshops are situated in the larger spaces of the original structure, thereby juxtaposing the two versions of art.

In the new construction outside of the Courthouse the gallery spaces and curatorial spaces are adjacent to allow a continuous dialogue between the production and display of art. This kind of interaction also occurs in other locations however, such as in the studio spaces, into which the gallery spaces are integrated but not focused upon a curatorial aspect.

As an urban artifact the condominium tower is multi-directional in its interaction with its surroundings and upon first impression has no linear spatial sequence, except for its verticality. In a more intimate path around the site it invokes the continuity of activities that have been integrated in the original buildings. This is achieved through the way it links to the interventions in the original buildings, which make a transition to the gallery in the condominium building by following a tight integration into the main circulation element. In fact, this element is an extension of the main circulation, past the walls of the original building, and forms the transition to the new gallery. Although the gallery has a 
separate entrance at the ground level, it may be reached through a transition space above that is embedded between the auditorium and gallery itself. It is at this point that a change in scale occurs in relation to that of the residence's vertical presence. In this contrast of scales, and reconciliation of urban presence with spatial narrative, various points of engagement with both the existing structure and the streetscape mark its accessibility. This reinforces the Condominium's presence in the precinct as one that is supportive of the activities insofar as its integration with its surroundings renders it, along with the plaza in which it is situated, a preface to the rest of the precinct. The residence tower most strongly resonates with the arts precinct in the relationship between the lobby space and gallery spaces. The lower levels of the tower house the permanent gallery collections that are curated. A glass lobby of the tower is surrounded by gallery walls, resulting in the residents being immersed in the art upon passing, and the gallery visitors being constantly exposed to activities of everyday life.

Circulation is critical to the spirit of the precinct. The public nature of the strong programmatic links is amplified due to the way one moves through the precinct. In this sense there is no end to the spatial narrative, but like a kind of urban circuitry, movement is continuous; the public will always wander through. The pedestrian may meander in and through; art is brought out as a part of the city, to absorb however transient, as an afterimage. 


\subsection{The Realm of the Artist}

The program, or activities relevant to various disciplines, includes the performing arts of dance and theatre, visual arts, and literary and media arts. Additionally, circulation, an urban circuit that filters movement in different directions, is considered a critical part of the program. As an initial step the insertion of a path for circulation enabled the larger spaces to be organized among and in relation to it. This in turn facilitated the articulation of boundaries between the various activities themselves. Existing walls could be acted upon in different ways so as to engage with the circulation element. This was done by removing walls to make relationships possible, breaking through walls and engaging walls by redefining existing conditions. It became clear that physical passage and accessibility became a dominant factor in the breaking down of barriers within the realm of the artist. Essentially, engaging walls as a strategy was initiated as a reaction to create passage. Visual passage was established in other instances where physical passage was not necessary or undesirable.

In other cases, existing barriers are redefined as other entities. The interior and exterior conditions demarcated by the walls have been modified by engaging them in ways so as to re-inhabit the spaces in between. This has occurred for instance, at the jail wall along Waller and Mackenzie King Bridge. The plane of the wall has been expanded into an inhabitable space by intersecting it with a structure that will house artists' studios (a facility which

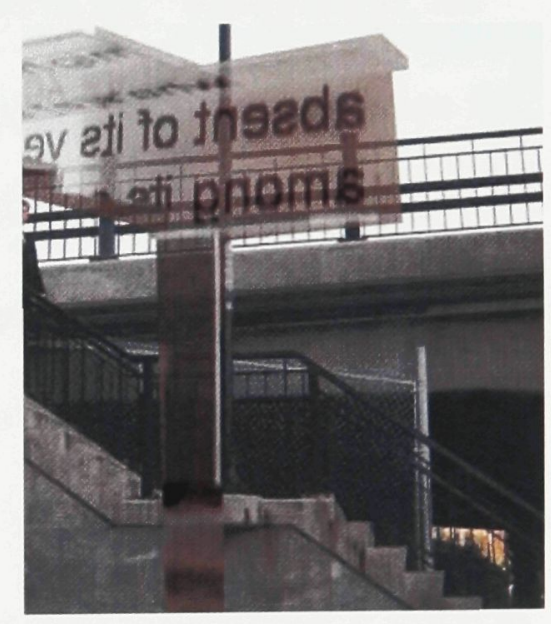

Figure 34. South-facing studios extend beyond jail wall to shelter stairway. Image bv author. 2006. 
is not offered at present but is needed). The studios accept, but challenge, the jail wall's presence, albeit 'lightly,' by providing a visually permeable structure that forms an urban artifact, clearly visible to both pedestrian and vehicular traffic. The transparency of its glazing will allow for the display of poetry or images, scaled to be legible to the occupants of the moving vehicles.

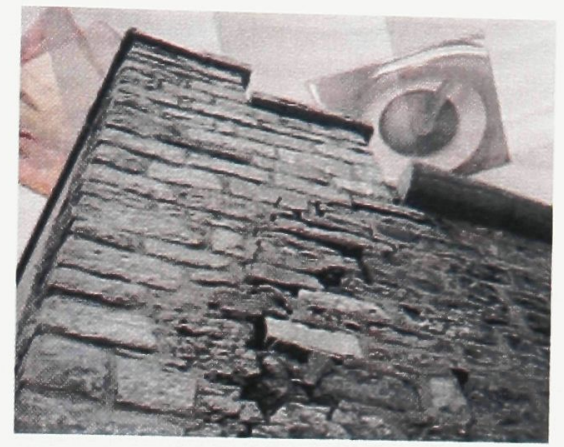

Figure 35 From sheltered stairway. Objects displayed overhead.

Image bv author. 2006.

\subsection{The Realm of the Viewer}

From the perspective of the viewer, the boundaries I have attempted to transgress concern the viewer's relationship to and experience of art. Critical questions such as whether there exists a moment of completion for a work to be displayed, relates to the viewer as well as the artist, albeit in a different way. By virtue of engaging the viewer differently, by focusing on the experience of the 'place' and the context of the consumption of the art works, can one increase the viewer's reflection upon the work of art? For example, the visibility of other activities, such as the processes art works go through in preparation for display, would have an impact on how someone appreciates the work. Engaging the viewer in such a way deviates from situations that limit communication between the public and the organizations. One visits the precinct not only for the absorption of art works but for reflection in return. Finally, if a dialogue is to be established between the vibrant, community oriented world of art and the institutionalized world of art, it needs to be mediated between the image of art as institution and the experience of it in its multiple elusive layers that interject aspects of artistic production in its display. It is in the 
boundaries between the production and display of art that these effects have been found to reverberate.

\subsection{The Shared Realm}

Reconsidering the relationship between primary and secondary spaces has enabled the redefinition of boundaries between art and the viewer. For instance, subverting the relationship between what is thought to be educational and operational or even administrative space opens the visitor to a new learning experience that is no doubt part of one's experience of live performances and exhibitions. This occurs in instances where spaces of production are juxtaposed with spaces of display; workshops, curatorial and preparatory operations with exhibits. The context of the gallery, and in this case the entire precinct, is no longer defined by residual passages amidst the confines of the walls in each room. Instead, one experiences the activities of artistic production. The boundaries between artistic production and the exhibit in its final form are what relate the realm of the artist and that of the viewer and the path that one takes through the building articulates those boundaries. The two are therefore connected or separated by the dialogue between the spatial narratives of each.

With respect to programmatic elements of exhibit activity, temporary and permanent exhibits are visually integrated to an extent with preparatory and conservation work space while still being associated with the larger circulation elements that traverse the building. Performance spaces and rehearsal spaces share a similar relationship. The theatre studio protrudes from the boundary of the existing wall out into the space between it and the 
jail, offering glimpse of rehearsals. This kind of relationship also occurs by engaging walls in other ways. Openings are reconfigured into thresholds for pedestrian passage, as in the entrance ramp off of Daly

Street, which forms the market approach, in between the Registry office and the Courthouse. This creates views of physically inaccessible spaces, while it celebrates interstitial spaces. A pedestrian's passage through the existing building

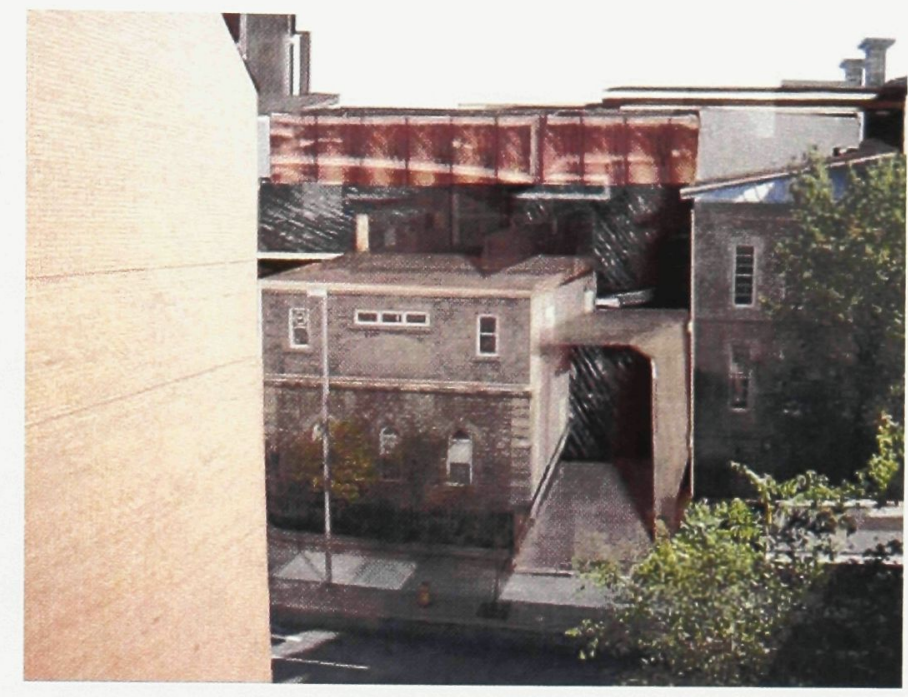

Figure 36. Approach from North side. Image by author, 2006.

is filled with moments where exhibits are accessible without making the 'gallery' a destination. The idea that the gallery does not need to be a destination per se for the pedestrian to meander through and be a part of the activities brings up the question of the redefinition of the gallery itself into a different type of place. The neutral, decontextualized room that is the typical conception of a gallery gives way to a live place of artistic production.

In Castelvecchio, rather than commonly displaying works of art objectively against a blank wall, the works are singled out as entities unto themselves and distinguished by the armatures of plaster, wood and brass on which they are presented. The works of art waver between being exhibit pieces and components of the building iself. Scarpa's treatment of the relationship between the way in which a work is displayed and the work itself signifies his awareness that the work is extremely vulnerable in this engagement. The 
works fluctuate between belonging to parts of the building and to parts of the exhibit, thus merging art and architecture, in two additional ways.

One involves the strong reciprocal relationship between the scale of the building and that of the works of art in the sense that individually contructed 'spatial moments' inevitably feed into and are projected into the whole, the entirety of the place in its language and sensibility. It is reciprocal in terms of the inability of one to grasp which, if any, occurs first. Thus, no overall strategy in any totalizing sense of a 'concept' to Castelvecchio can be attained beyond one's interpretation.

The other involves the treatment of light as an intermediary between the art work and the building, not isolating the treatment of either but washing both with daylight. ${ }^{10}$ The way in which a viewer engages with art works is guided and heightened by releasing the work from the realm of the wall's and floor's suface. This enables one to approach the work from different directions since it defines its own realm within each space, and activates movement around it.

Similarly, in the Arts Precinct, walls have been engaged in other ways so as to organize work spaces and exhibit spaces to redefine existing conditions. This has occurred in the exhibit in the Courthouse associated with the school aspect. There, workshops serve the dual function of exhibit space by virtue of a pivoting wall. Displaying work in such a manner, probes the final moment that a work is complete and ready to display. At the end of a class, artists and students may turn a portion of a wall upon which the work is

\footnotetext{
${ }^{10}$ Giovannini, Joseph. "History's Architect" in Art in America, New York: Brant Publications Inc, Oct 1999.
} 
mounted, to offer a glimpse of it to pedestrians passing by. This also occurs in the exhibit spaces associated with the art school program in the Courthouse. In this case however, the surface of the floor has been engaged instead of that of the wall, creating a vertical connection. This would facilitate the installation of a pulley system for preparing, lifting and displaying works on upper levels of exhibit space, affording visual accessibility of such activities in a true immersion of production.



\section{Conclusion}

Scarpa's approach to museum design in a historic building has had a substantial influence in helping me to challenge and articulate boundaries. It is clear that the reinterpretation of the heritage building cannot occur independent of the events that happen there, and positive relationships can grow out of the results of mimetic historic preservation and conventional gallery design. Redefining boundaries can help to reconfigure a person's relationship to his/her surroundings and introduce the viewer as narrator in his/her passage through the space.

The program of the art gallery has been developed to reveal the art gallery in the city as a device that connects it to the city - one that is meant to absorb the activities of the city and return them tenfold. The place that is the Arts Precinct embodies the narrative as a place of live art. It is precisely because of the nature of the narrative that the liveliness of 
it depends on the viewer, or pedestrian as participant in such a place. The thesis builds on this relationship at two merging scales. One scale is that at which the viewer, as a participant in the urban narrative, engages with the place and the activities that make the place operate as such. The other scale is that at which the viewer engages more intimately with the art works.

The French philosopher, Paul Ricoeur, writes about the connection between multiple incidents, or events, in a story. An event transcends mere occurrence and not only contributes to the beginning and end of the story, but also to its progress. The Arts Precinct has been designed with the intention of providing multiple events that can be configured into a variety of narratives. Specifically included in these events are those aspects of the program related to the production, and not simply the display of art. This development reinforces the narrative of the arts precinct as a centre for public discourse and political and social artistic activity. As a live place of artistic production it thrives not only on a multiplicity of possibilities that unfold upon entering, but on the necessity of the reader to draw meaning from his/her surroundings. It is in this sense that Paul Ricoeur makes the argument that the emergence of the meaning of a story exists in the intersection between the two worlds of the text and the reader. ${ }^{11}$ In the case of the arts precinct, the narrative unfolds at the intersection between the world of the artist and the world of the active viewer; articulated through the architecture's spatial relationships.

\footnotetext{
${ }^{11}$ Ricoeur, Paul. "Life: A Story in Search of a Narrator", in: Doeser, M.C. (ed.), Facts and Values, Dordrecht: M. Nijhoff, 1986. 121-132.
} 
The intent of the thesis has been to engage people in rethinking whether existing preconceptions that have contributed to the isolation of the building, were appropriate. Its purpose stands as a device of resistance to certain conceptions of space that have resulted in a series of purely pragmatic strategies on the site. Hence, as a reaction to an existing configuration of relationships, another configuration emerges in the increased understanding of the possibilities when approaching a historic site as an urban artifact. Similarly, with respect to the role of art within the community, the intention is to reinterpret the institutionalized world of art by engaging its vibrant counterpart of artistic production. 


\section{Bibliography}

Albertini, Bianca, and Bagnoli, Sandro. Carlo Scarpa, Cambridge: The MIT Press, 1988.

Attlee, James, Le Feuvre, Lisa. Gordon Matta-Clark: The Space Between, London: Nazraeli Press, 2003.

Bennett, E.H., and Cousins, E.L. Report of the Federal Plan Commission on a General Plan for the Cities of Ottawa and Hull, January 1915. Courtesy of the City of Ottawa Archives 2005.

Castelvecchio Museum Website. 2006

$<$ http://www.comune.verona.it/Castelvecchio/cvsito/english/index1.htm>.

City of Albert Lea, Minnesota. Heritage Preservation Agenda. 2006

$<$ http://www.city.albertlea.org/hpagenda.htm>.

City of Ottawa Air Photos. 2002. GIS Data Catalogue 2005

$<$ http://www.library.carleton.ca/madgic/maps/gisweb/data/2002airphotos.pdfs.

City of Ottawa Topographic Maps.2003. GIS Data Catalogue 2005

$<$ http://www.library.carleton.ca/madgic/maps/gisweb/data/2k.htm>.

Confederation Square Development, Volume 1: A Proposal to the NCC, by John B.

Parkin Associates Architects and Engineers, December 1962.

Deleuze, Gilles, and Guattari, Felix. Kafka: Toward a Minor Literature, University of Minnesota Press, 1986.

Dal Co, Francesco. Carlo Scarpa, Milano: Electa Editrice, 1984.

Fire Insurance Map. Insurance Plan of the City of Ottawa, Underwriters' Survey Bereau Ltd., 1888.

Fire Insurance Map. Insurance Plan of the City of Ottawa, Underwriters' Survey Bereau Ltd., 1912.

Fire Insurance Map. Insurance Plan of the City of Ottawa, Underwriters' Survey Bereau Ltd., 1956.

Giovannini, Joseph. "History's Architect” in Art in America, New York: Brant Publications Inc, Oct 1999.

$<$ http://www.findarticles.com/p/articles/mi_m1248/is_10_87/ai_56906446>. 
Lundholm, Michael E. The Arts Court Executive Summary of Feasibility Study, Ottawa Arts Centre Foundation, May 1990.

Magagnato, Licisco. "The Castelvecchio Museum" in Carlo Scarpa, Milano: Electa Editrice, 1984.

Ottawa Arts Court Foundation. Pre-Feasibility Needs Assessment \& Best Practice Analysis 2: Needs Assessment/Stakeholder Consultation, 2006.

Ricoeur, Paul. "Life: A Story in Search of a Narrator", in: Doeser, M.C. (ed.), Facts and Values, Dordrecht: M. Nijhoff, 1986.

Vattimo, Gianni. The End of Modernity: Nihilism and Hermeneutics in Post Modern Culture, Great Britain: Polity Press, 1988. 


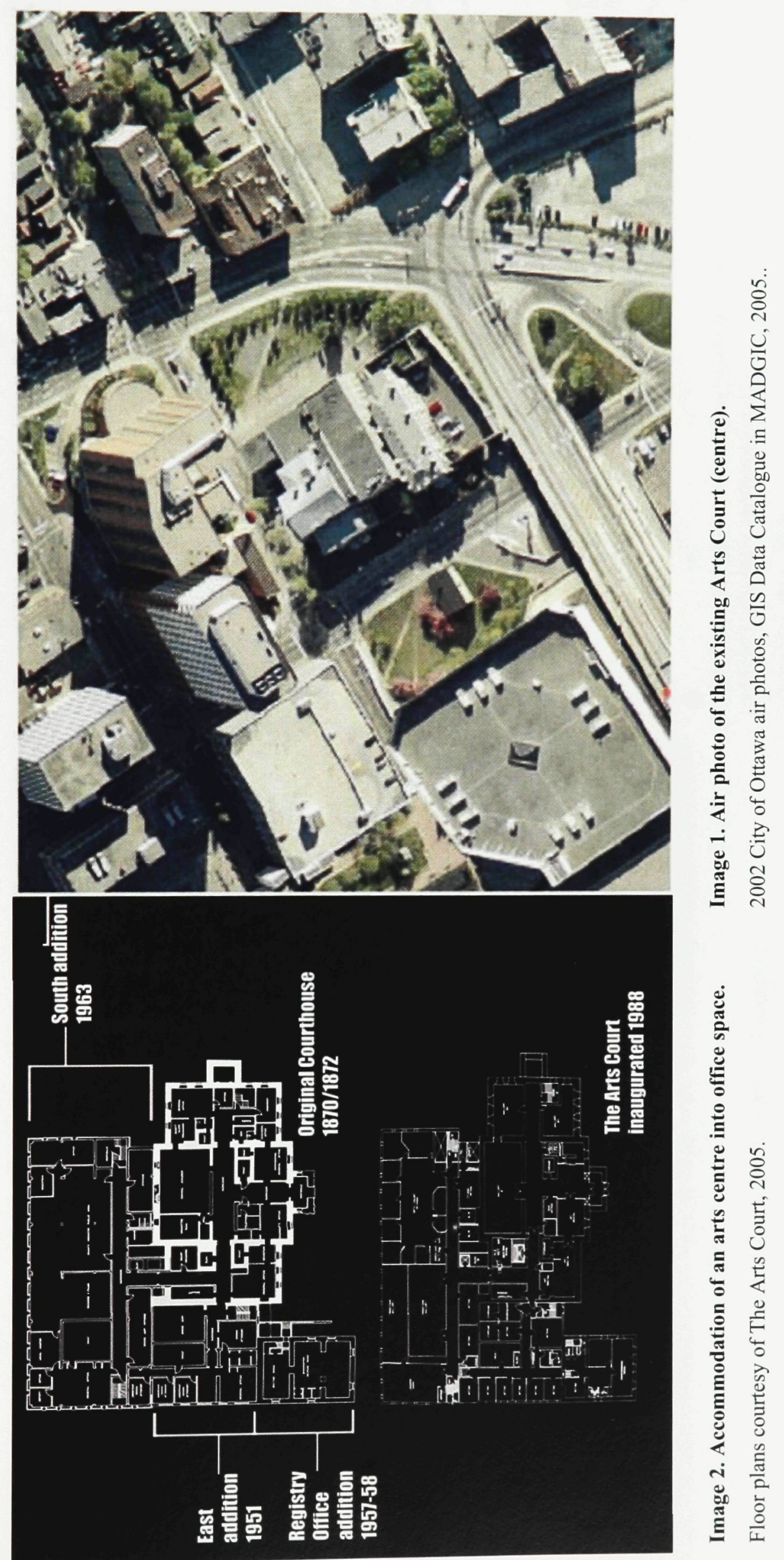



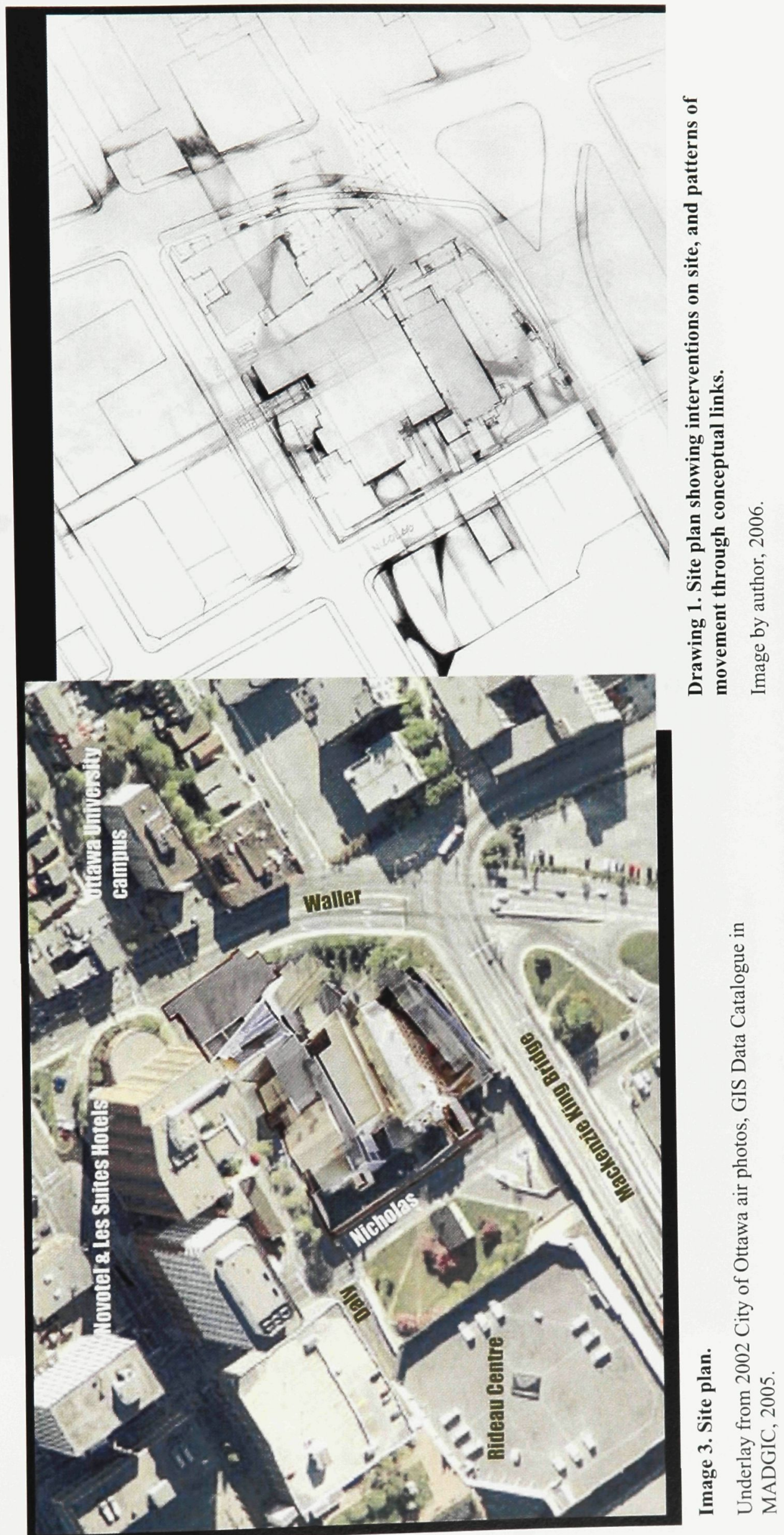


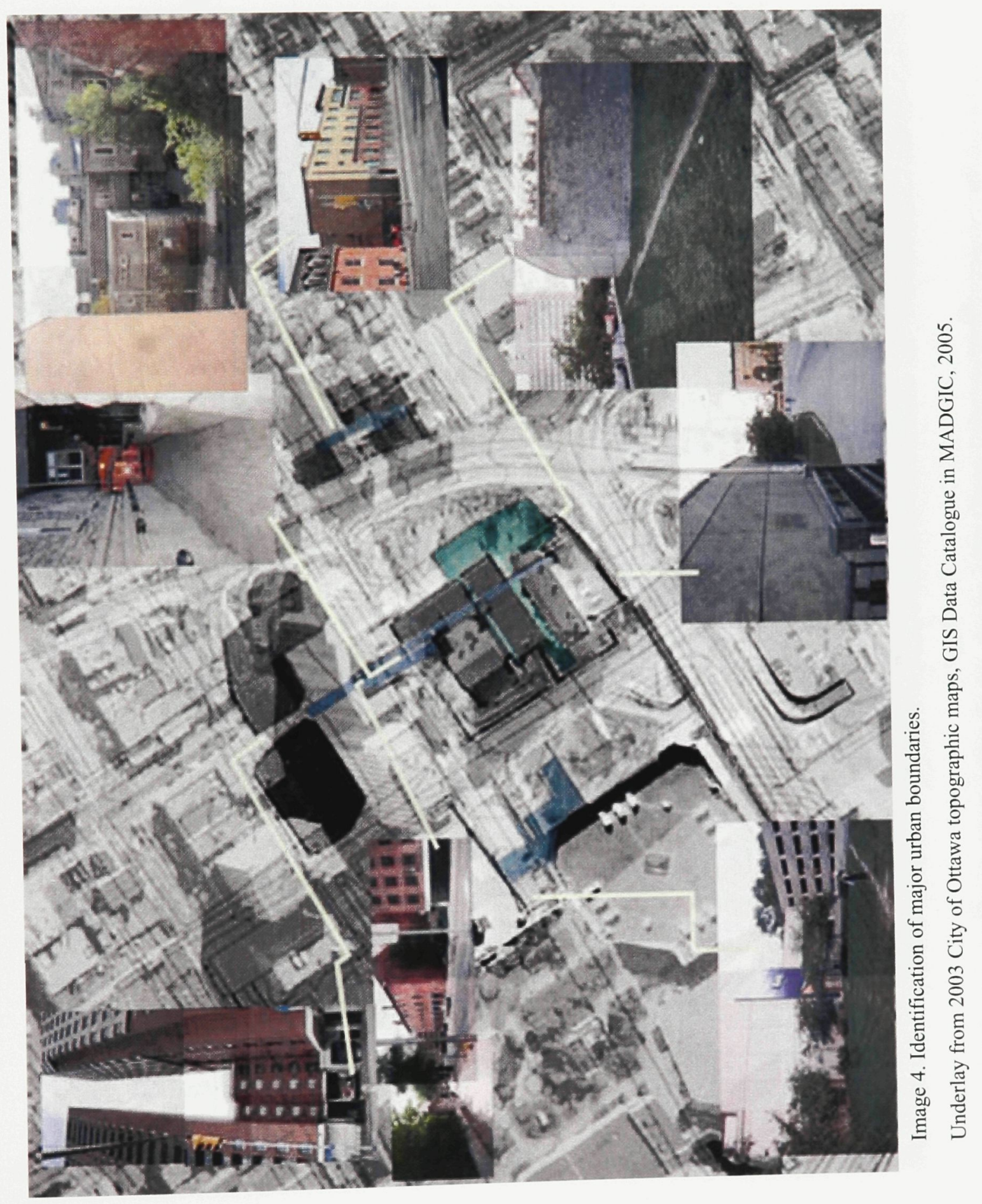




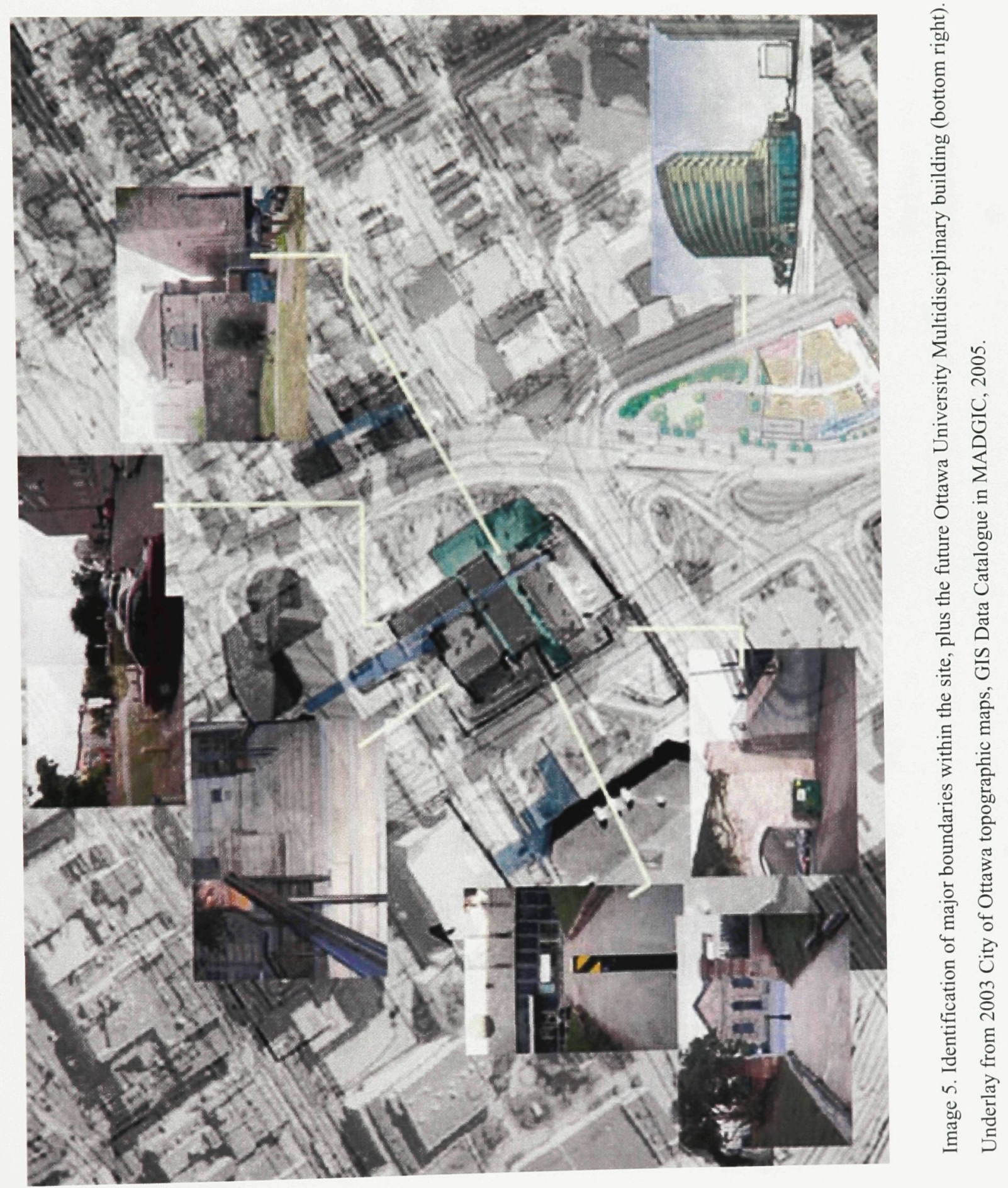




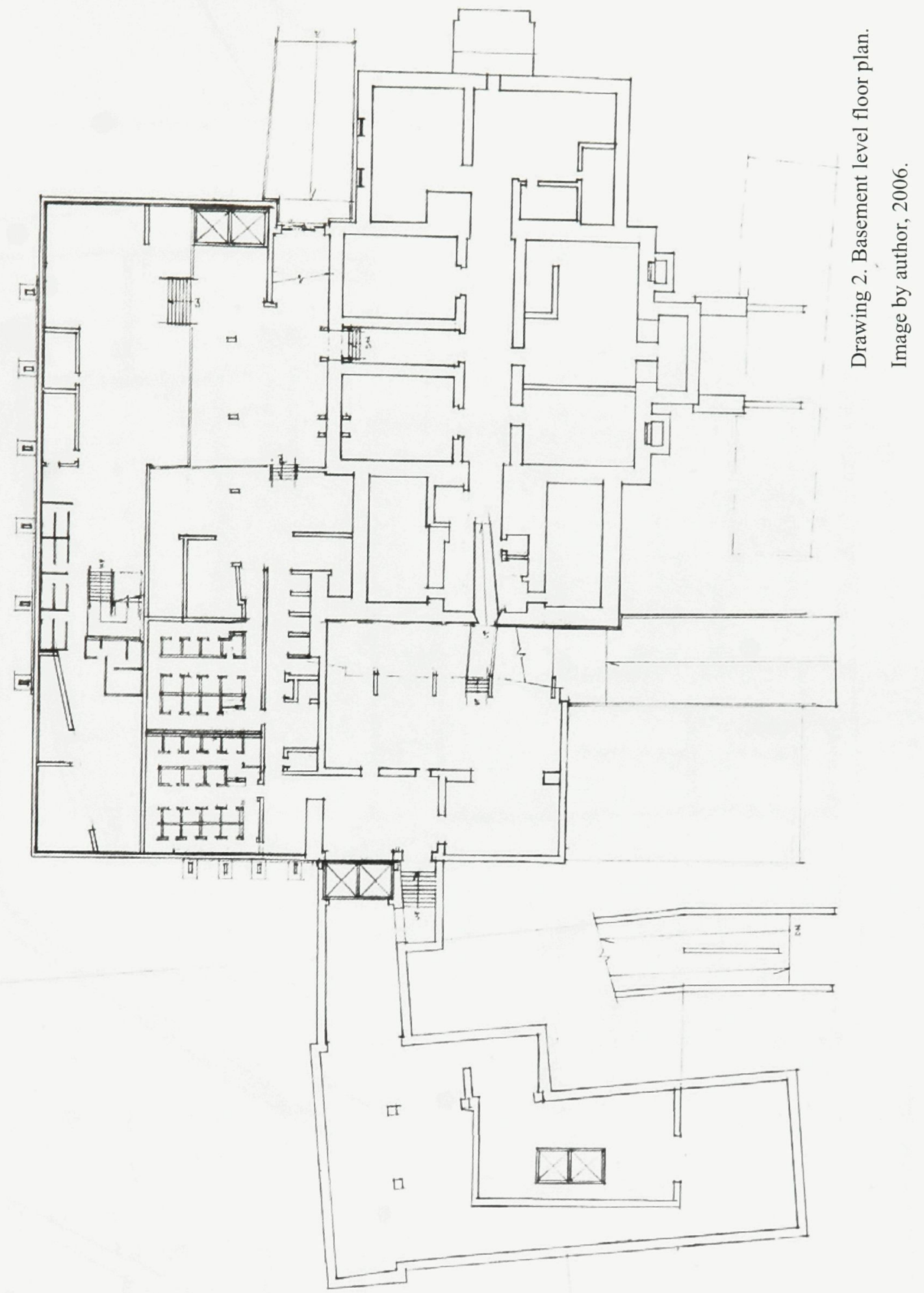




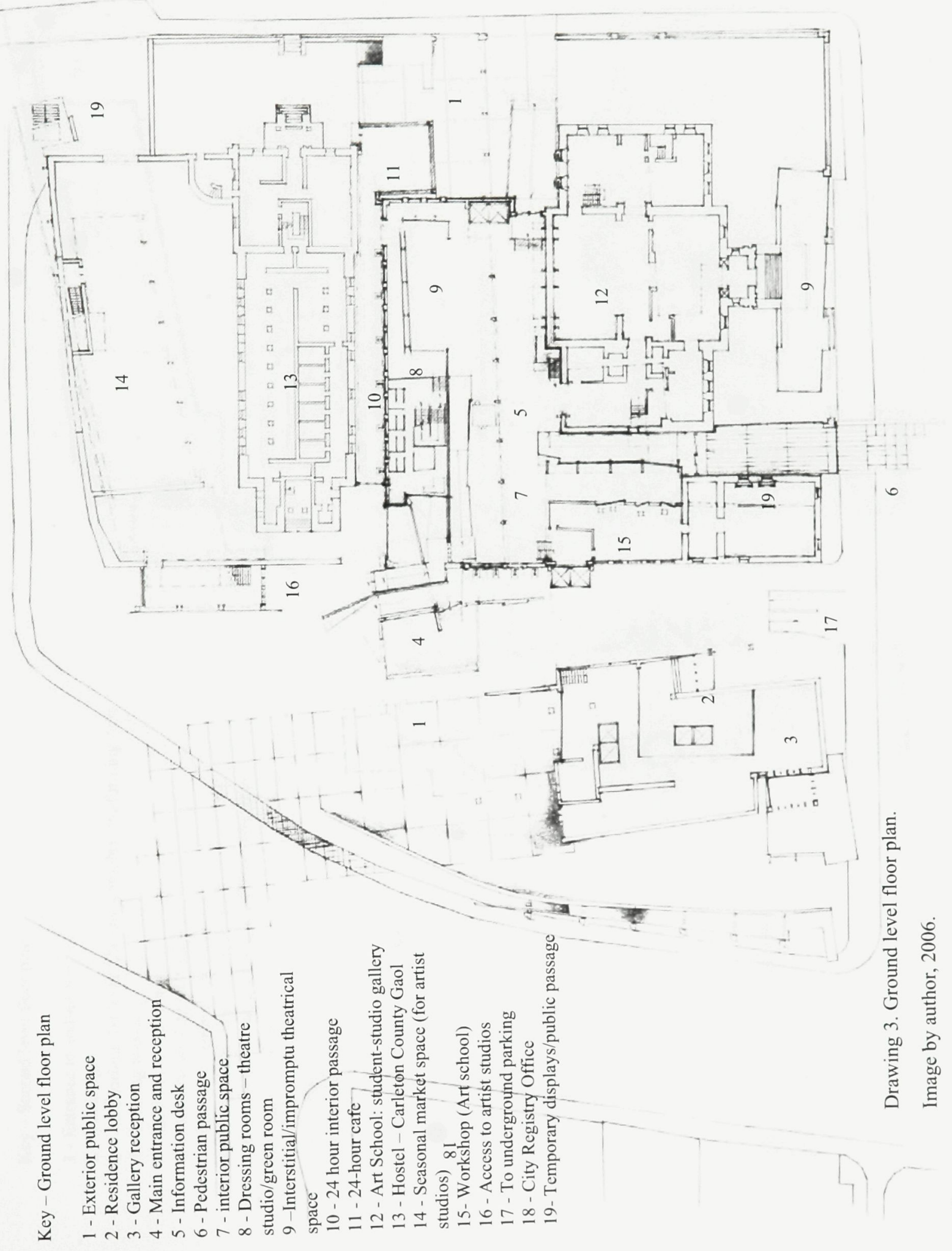









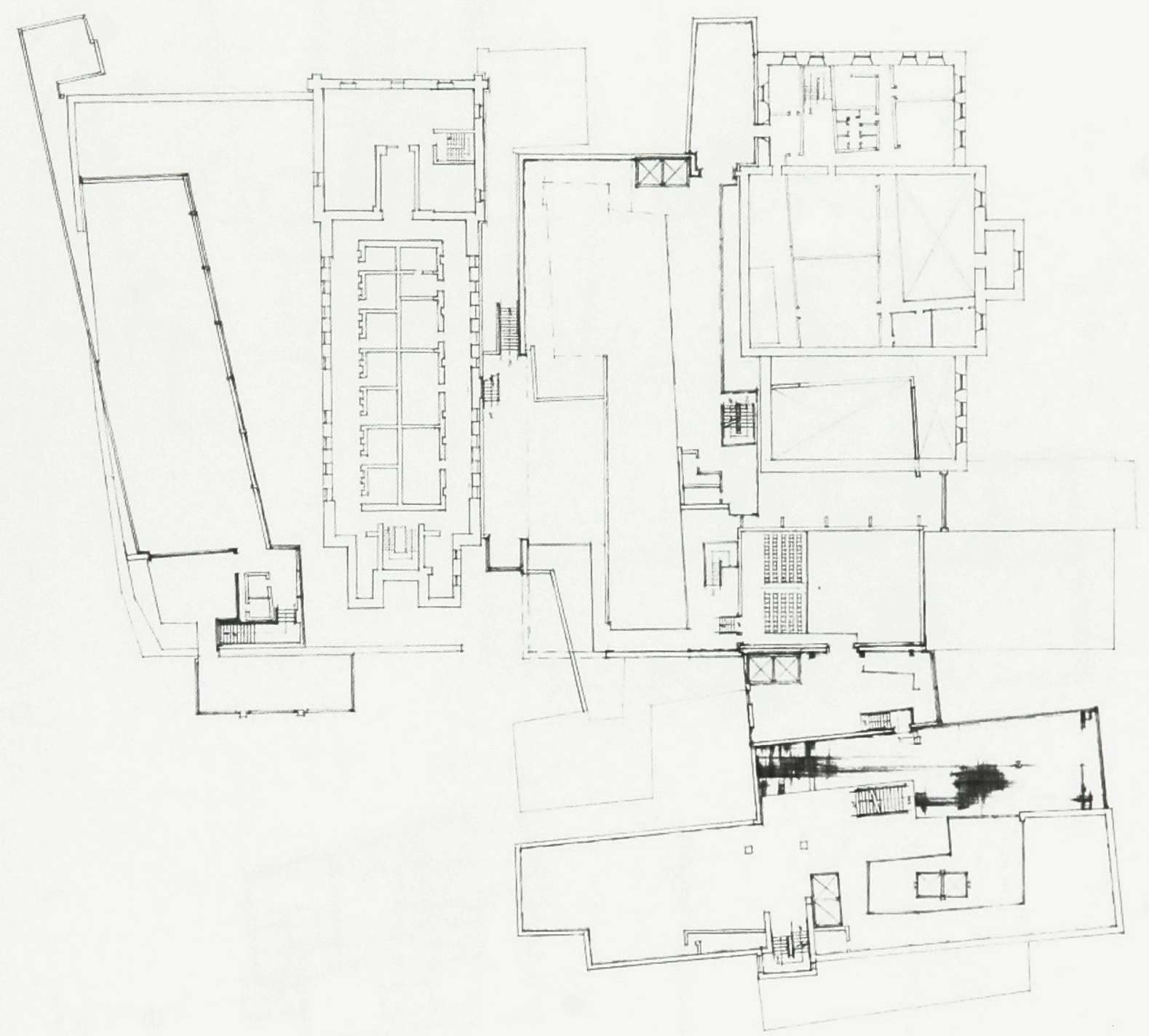

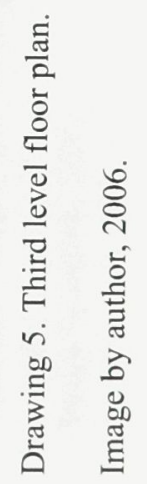









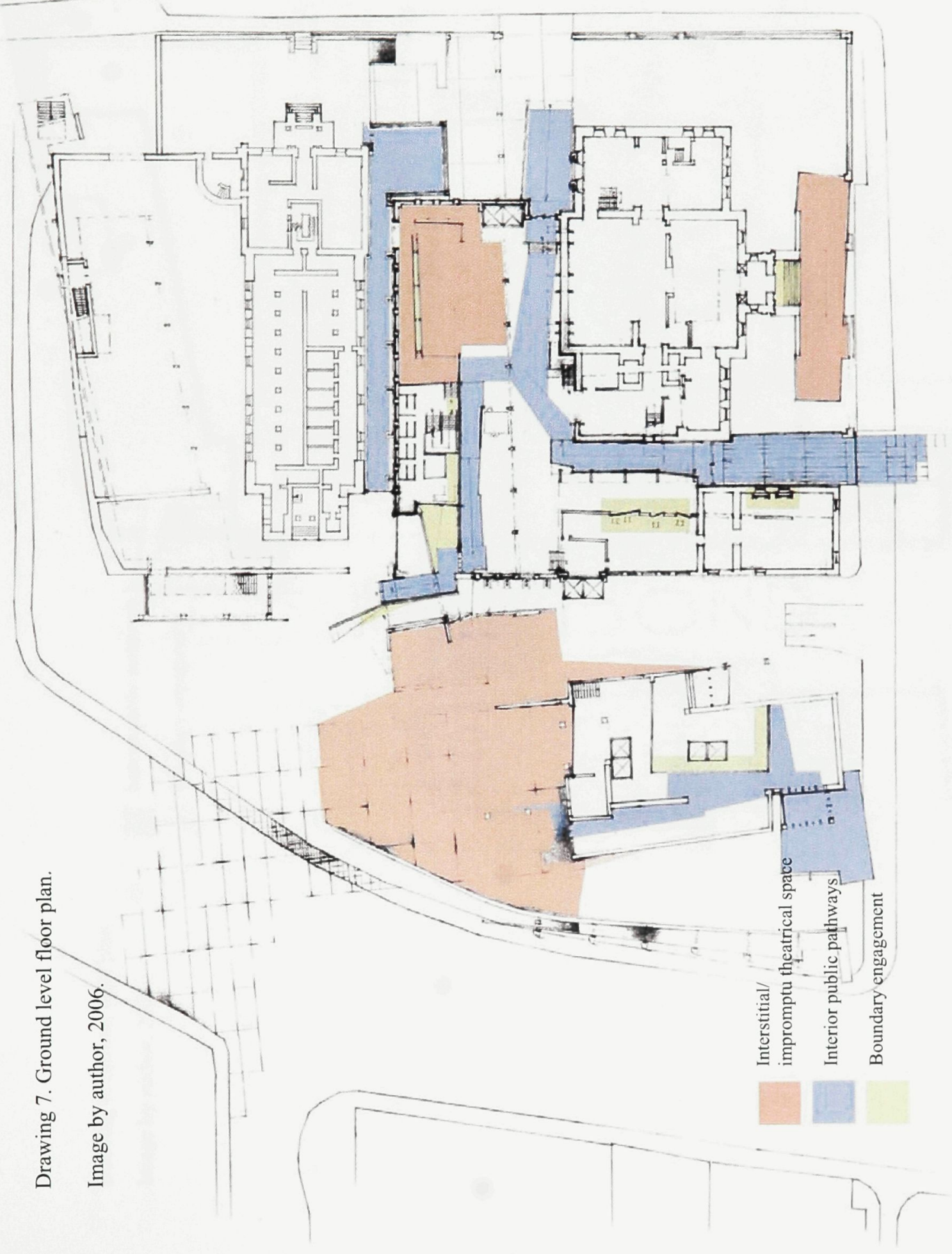




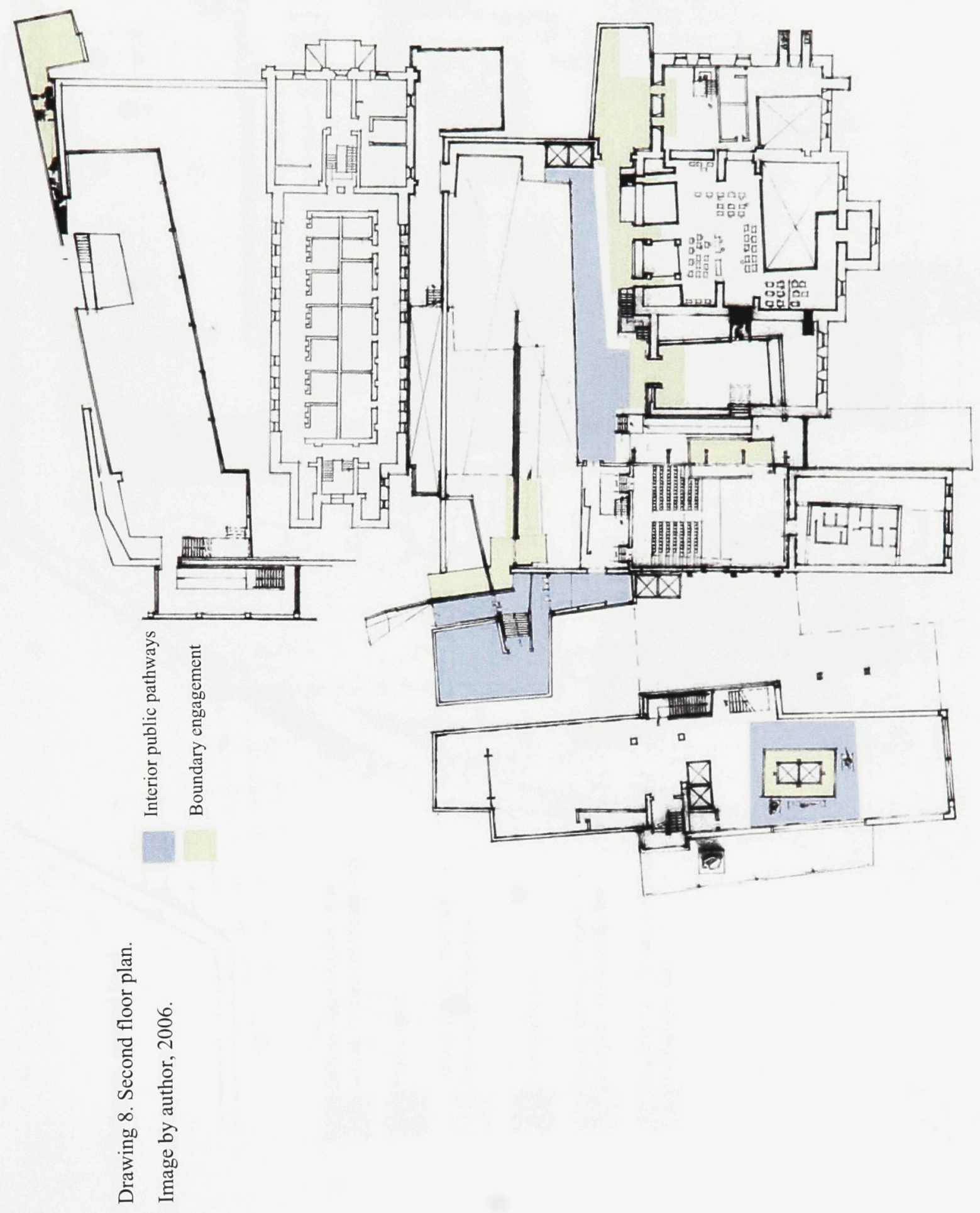




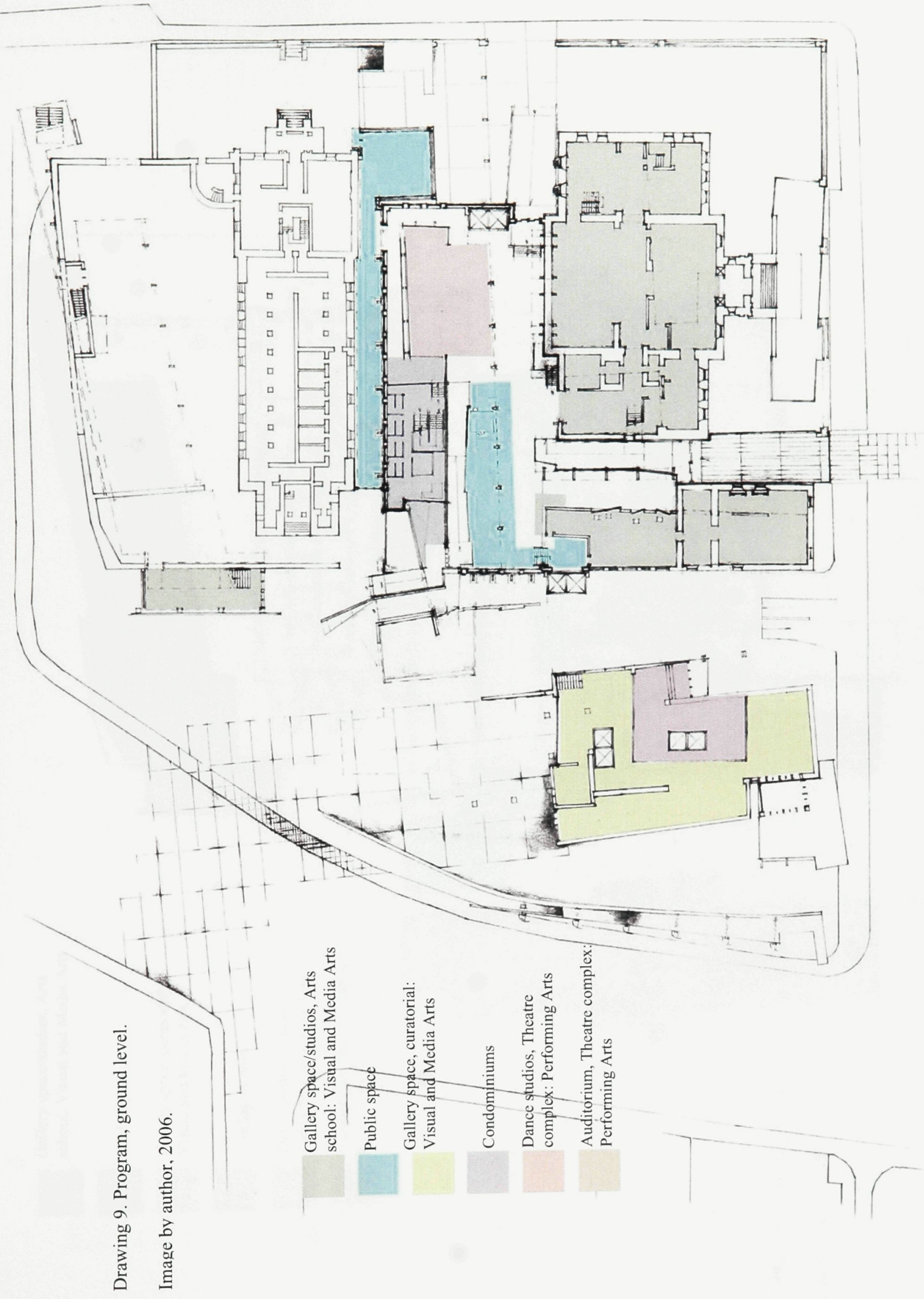




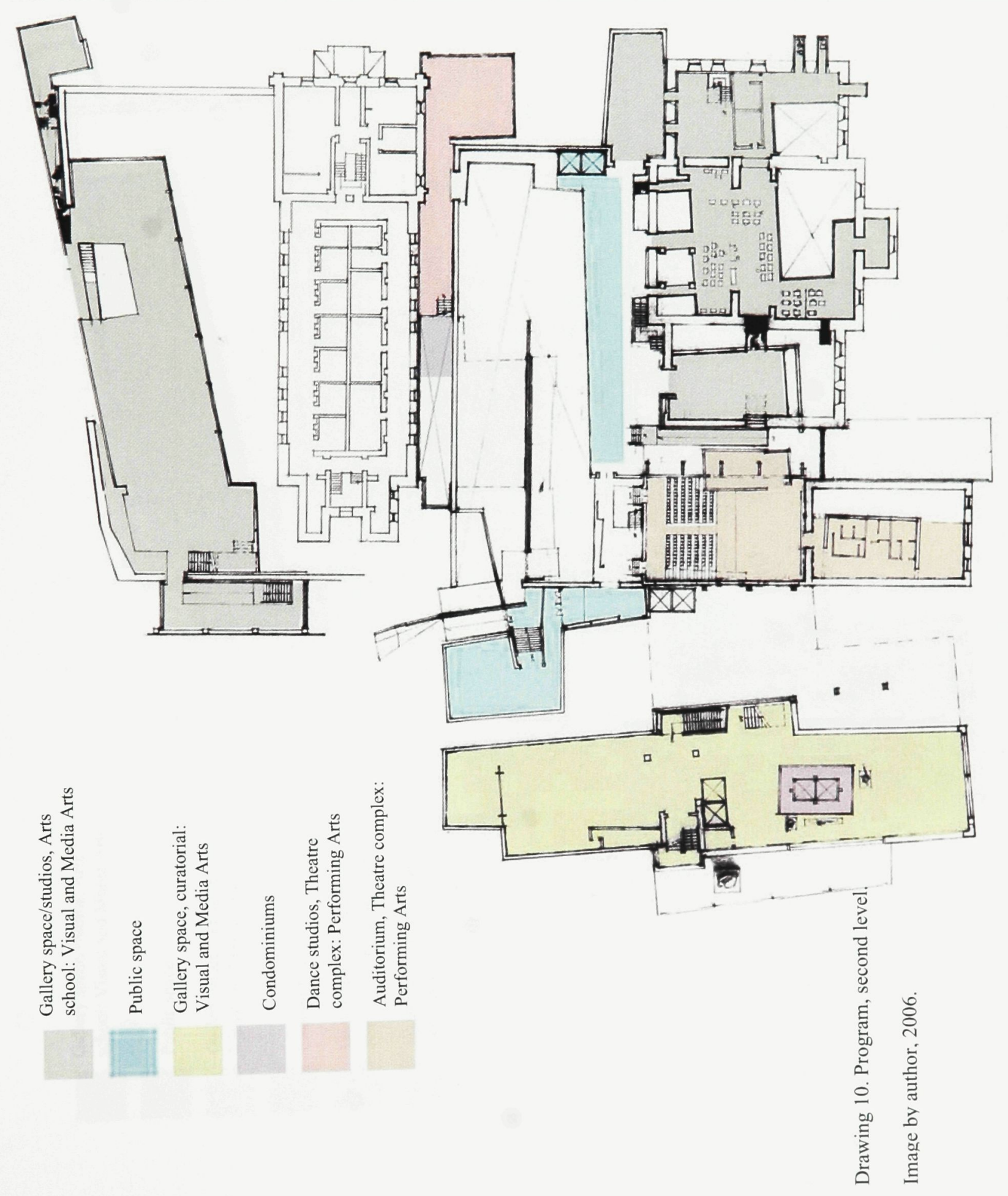









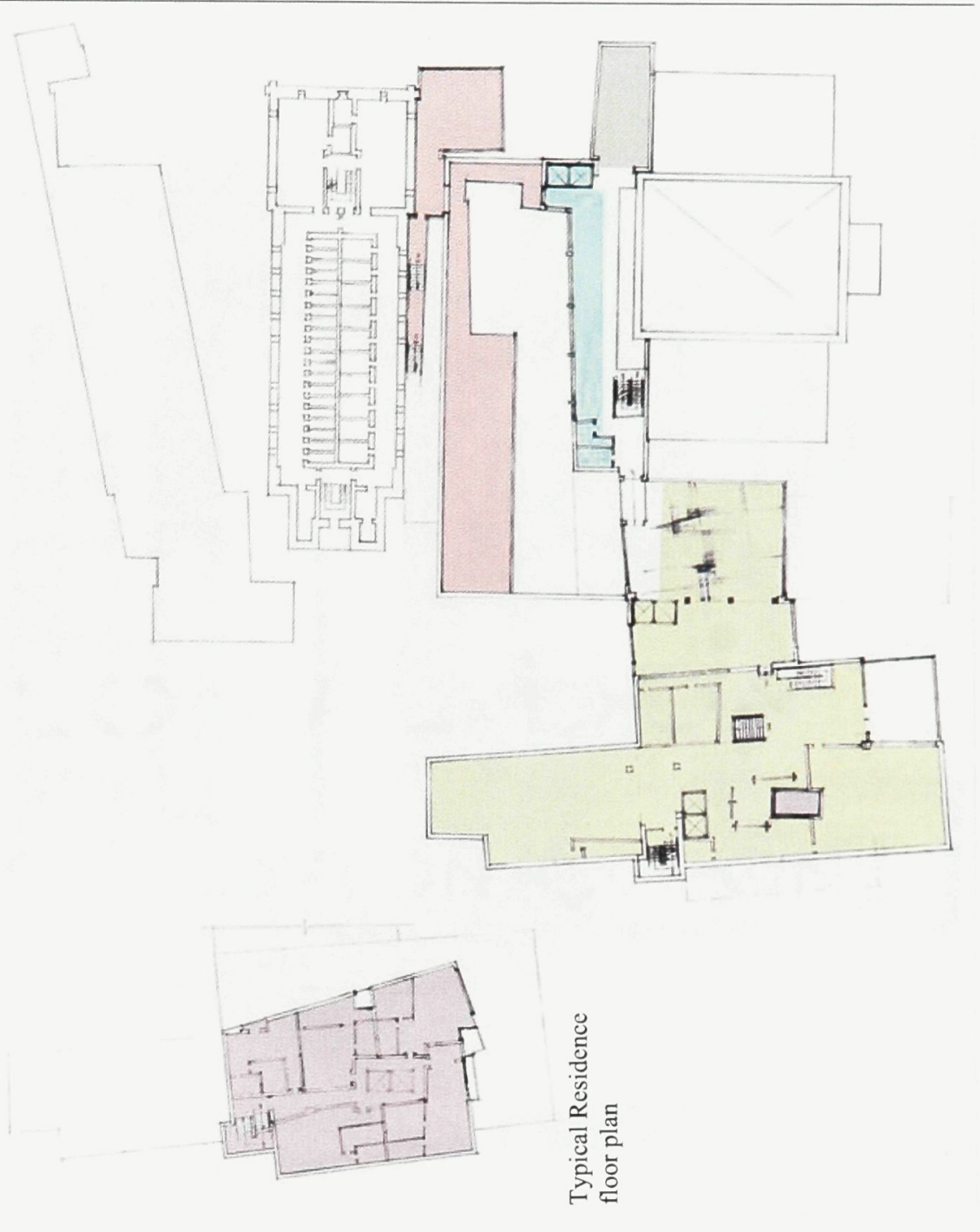

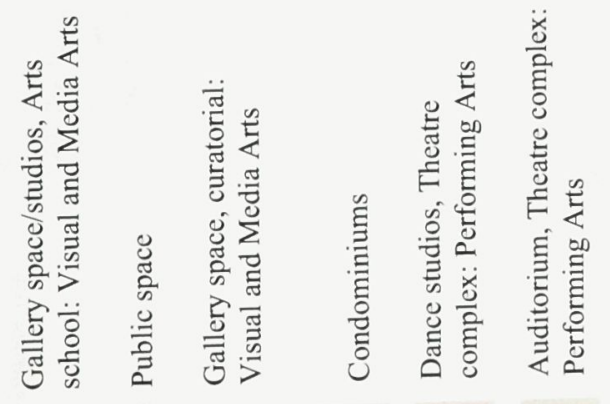

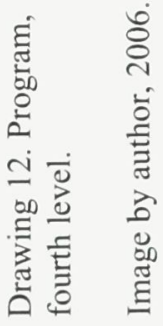




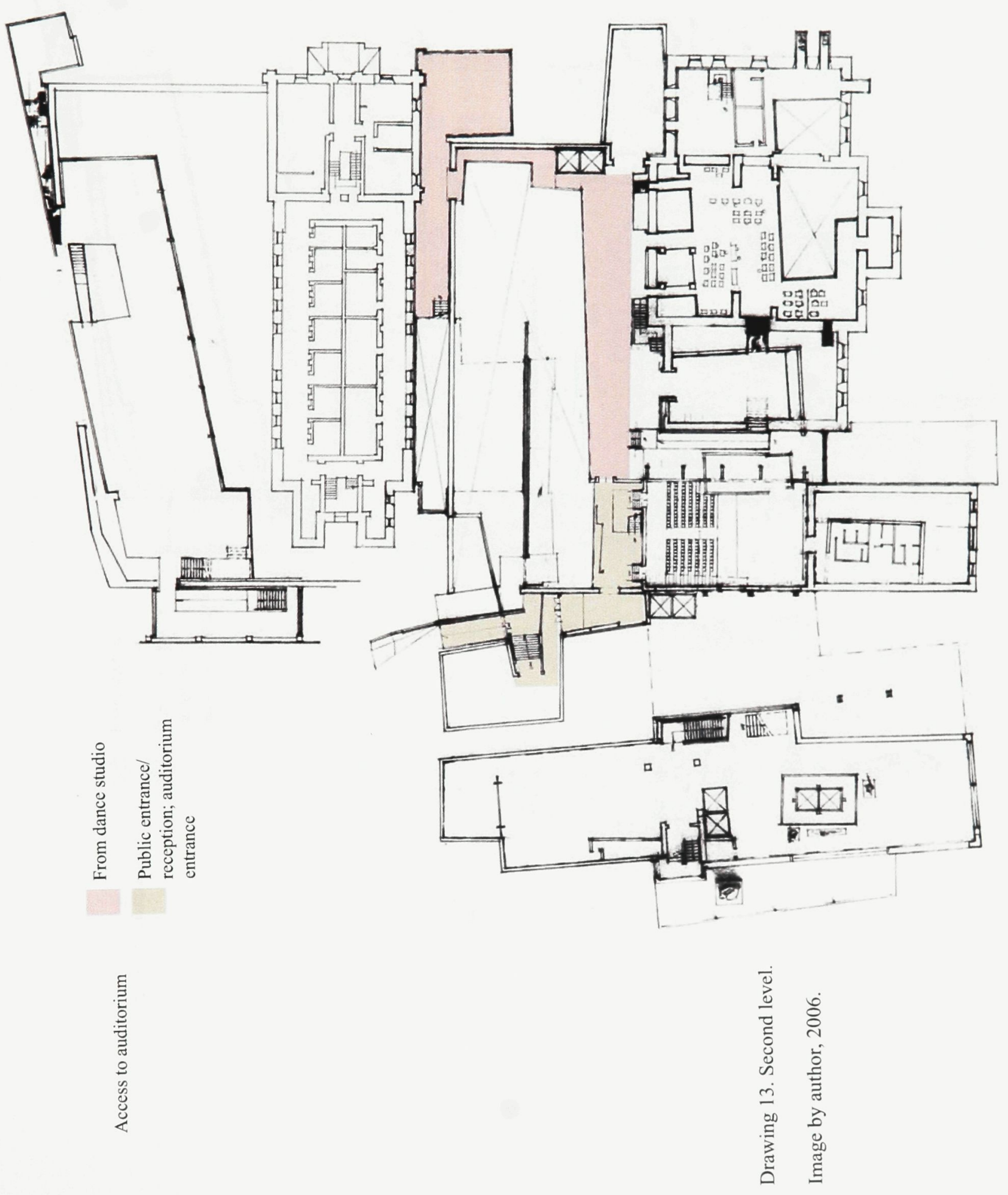









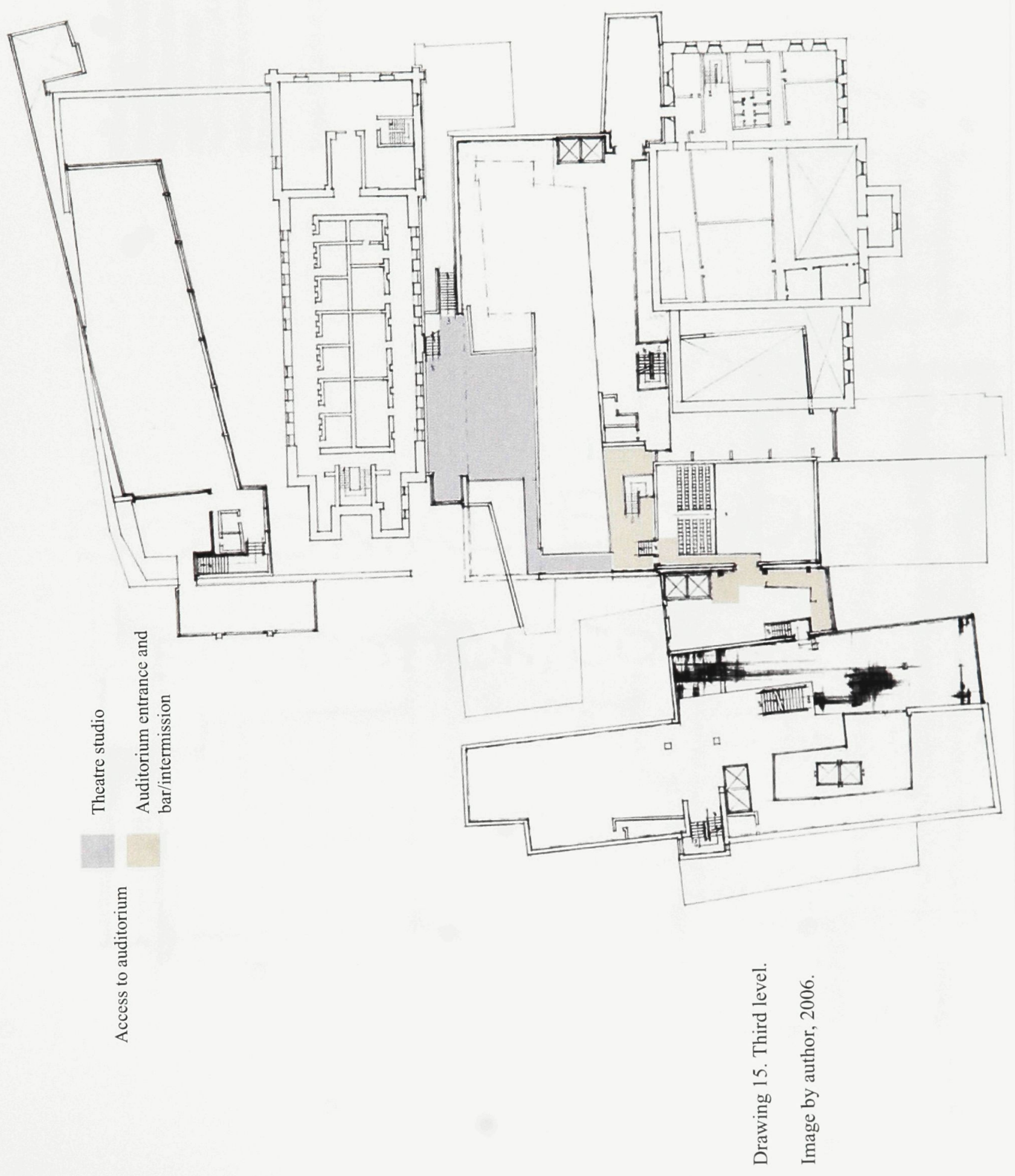





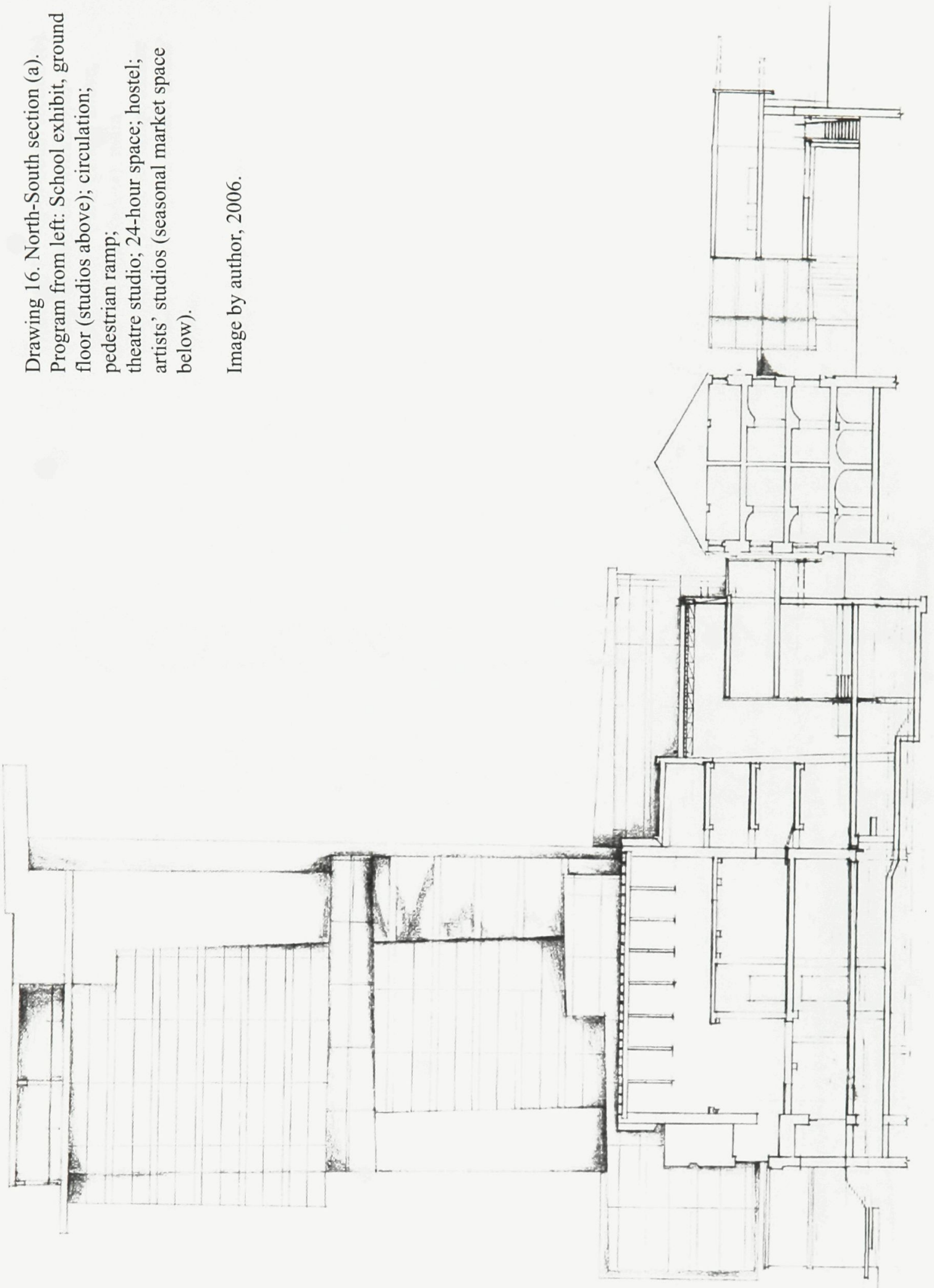


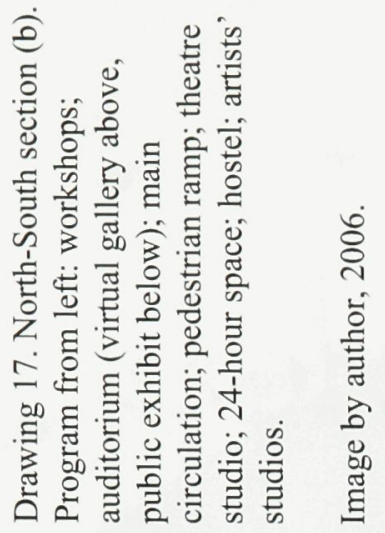






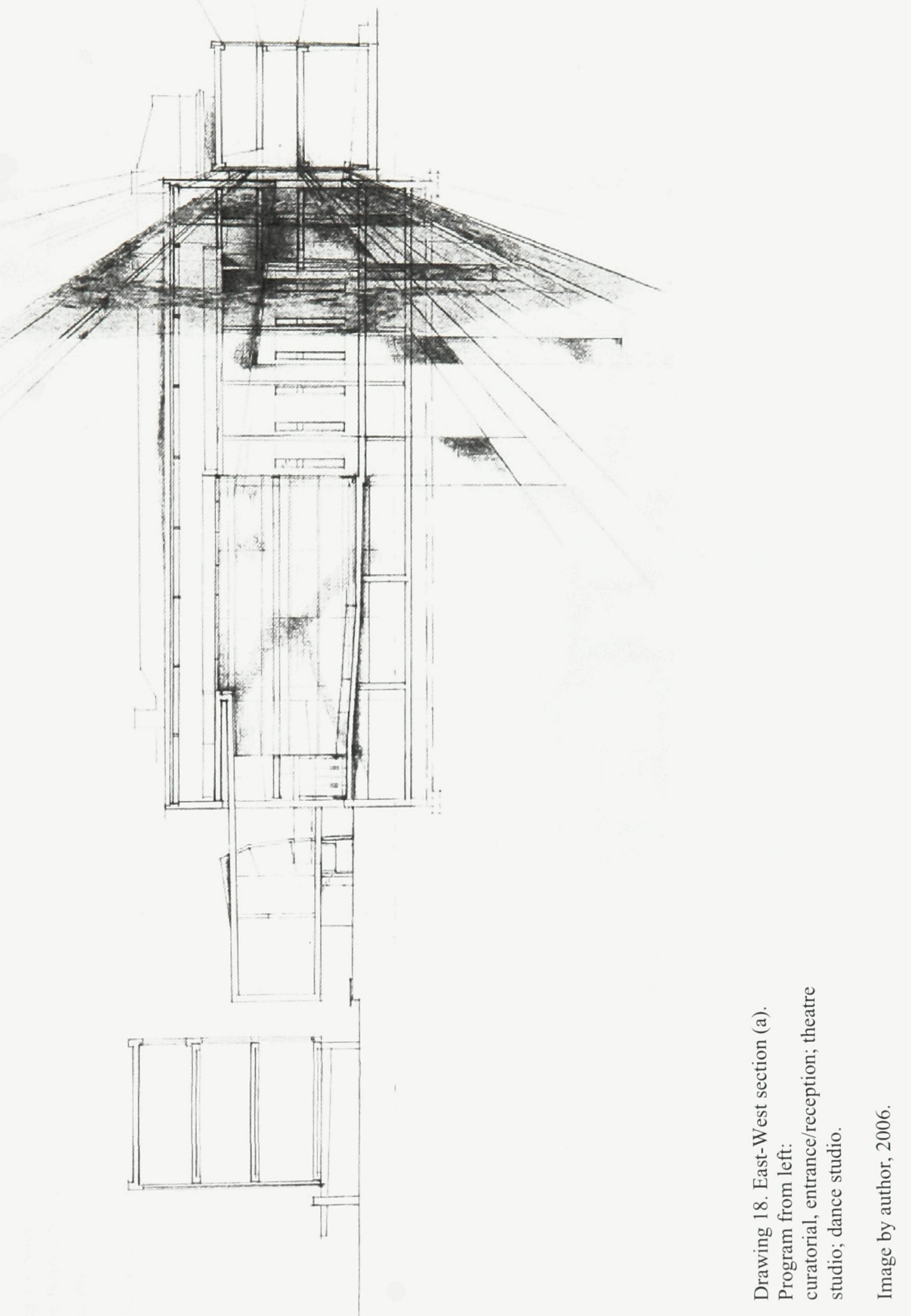




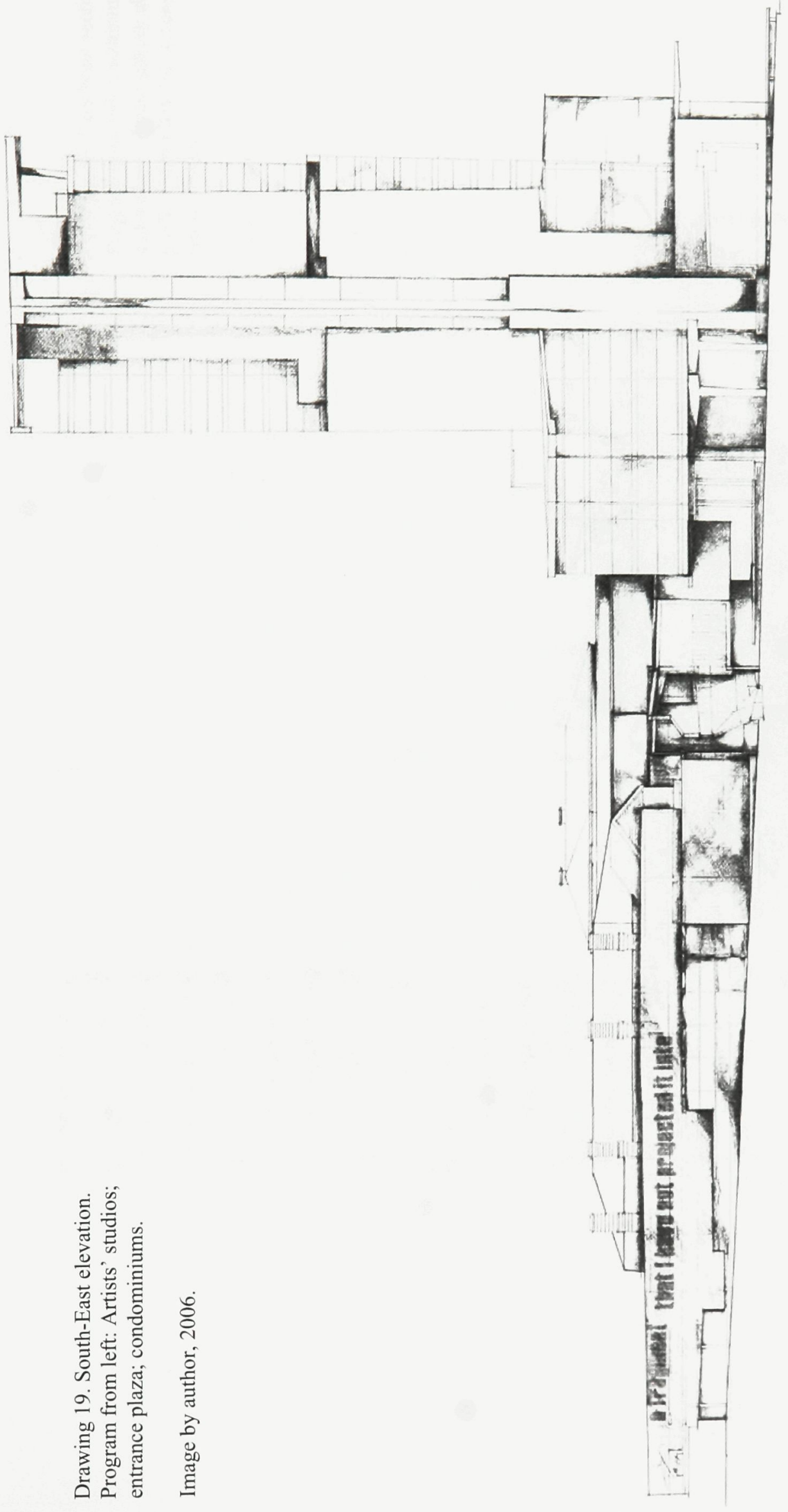



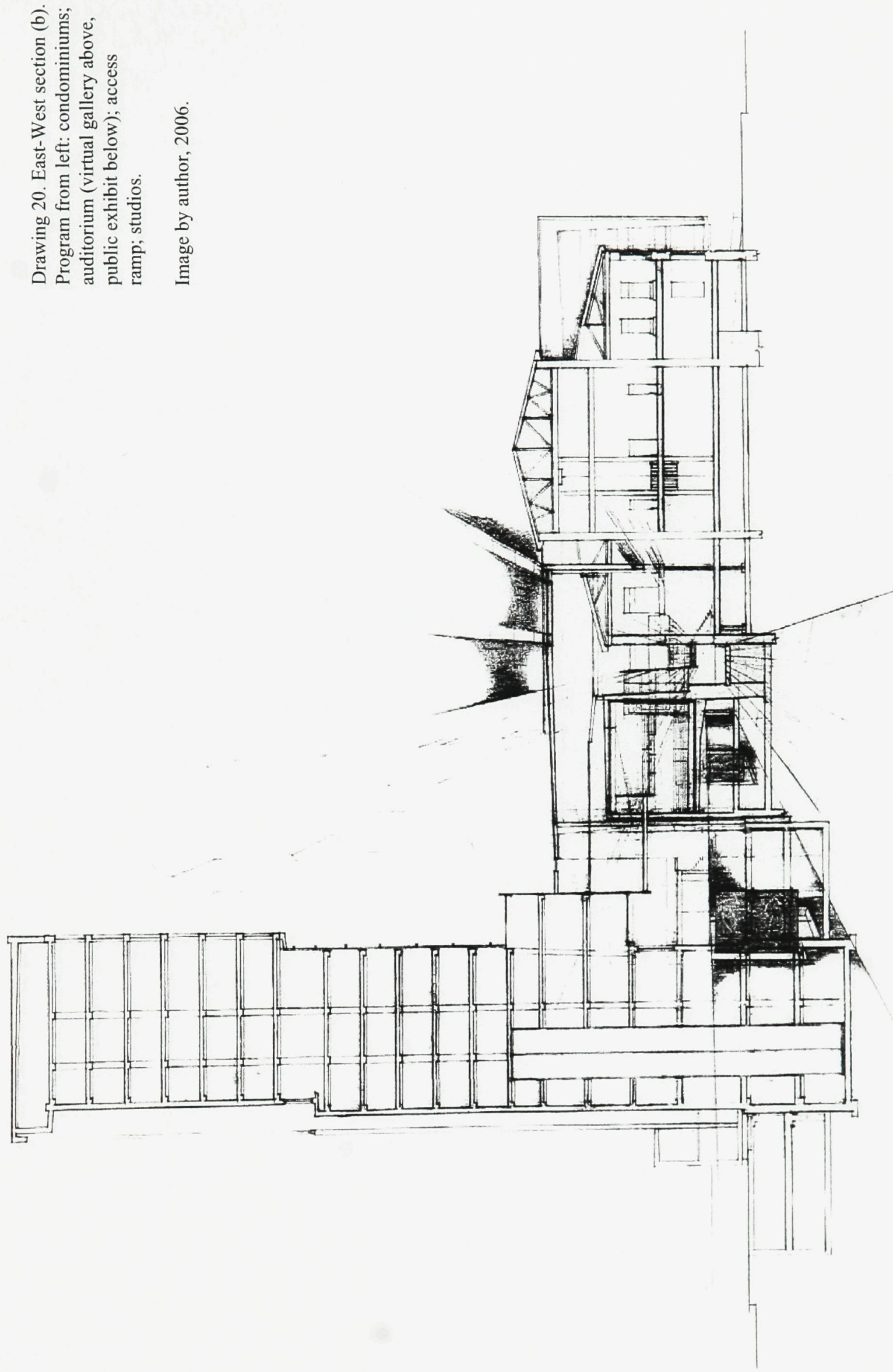